\title{
Combining Stochastic Optimization and Monte Carlo Simulation to Deal with Uncertainties in Climate Policy Assessment
}

\author{
Frédéric Babonneau • Alain Haurie . \\ Richard Loulou • Marc Vielle
}

Received: 31 July 2010 / Accepted: 1 April 2011 / Published online: 29 July 2011

(C) Springer Science+Business Media B.V. 2011

\begin{abstract}
In this paper, we explore the impact of several sources of uncertainties on the assessment of energy and climate policies when one uses in a harmonized way stochastic programming in a large-scale bottom-up (BU) model and Monte Carlo simulation in a large-scale top-down (TD) model. The BU model we use is the TIMES Integrated Assessment Model, which is run in a stochastic programming version to provide a hedging emission policy to cope with the uncertainty characterizing climate sensitivity. The TD model we use is the computable general equilibrium model GEMINI-E3. Through Monte Carlo simulations of randomly generated uncertain parameter values, one provides a stochastic micro- and macro-economic analysis. Through statistical analysis of the simulation results, we analyse the impact of the uncertainties on the policy assessment.
\end{abstract}

F. Babonneau $(\varangle) \cdot$ A. Haurie

ORDECSYS, Geneva, Switzerland

e-mail: fbabonneau@gmail.com

A. Haurie

e-mail: ahaurie@gmail.com

F. Babonneau $\cdot$ M. Vielle

Economics and Environmental Management Laboratory, Swiss Federal Institute of Technology at Lausanne (EPFL),

Lausanne, Switzerland

R. Loulou

KANLO Consultants, Lyon France

e-mail: richardloulou@gmail.com

M. Vielle

Toulouse School of Economics (LERNA),

Toulouse, France

e-mail: marc.vielle@epfl.ch
Keywords Climate change - Uncertainties • CCS • Monte Carlo simulation - Stochastic optimization • General computable equilibrium • Energy technology model

\section{Introduction}

The purpose of this paper is to evaluate the impact of uncertainty on the economic assessment of long-term energy policies designed to mitigate climate change. We identify four classes of uncertainties related to climate, technology, economy and energy prices, respectively. We propose a dual approach, based on the combined use of stochastic programming and Monte Carlo (MC) analysis to deal with these uncertainties in a technoeconomic analysis involving two complementary models. A stochastic programming approach is implemented on a bottom-up integrated assessment model, TIMES Integrated Assessment Model (TIAM WORLD) [28], to propose a hedging emission abatement policy for the time horizon 2030, followed by four typical recourse abatement policies, compatible with a target of $2.1^{\circ} \mathrm{C}$ temperature increase in 2100 , under reasonable assumptions on the uncertainty on climate sensitivity (Cs) [2]. The scenarios produced by TIAM WORLD take into account the Cs uncertainty but are based on perfect foresight assumptions for a lot of technological and economic parameters that could also impact the policy assessment.

To take into account the impact of these other sources of uncertainty on climate policy assessment, we use MC analysis on a computable general equilibrium (CGE) model, GEMINI-E3 [8], specifically designed to 
assess climate policies and which is run in a harmonized way with TIAM WORLD. The CGE is a multi-country, multi-sector, dynamic model running in annual steps from the base year 2001-2050. We take into account several sources of uncertainty pertaining to the general economic and technological environment, using MC simulations with Latin hypercube sampling [18] to obtain probability density functions (pdf) for the output variables of GEMINI-E3 that concern welfare gains, emissions abatement etc.

Recently, MC-based approaches have been successfully implemented on the Emissions Prediction and Policy Analysis (EPPA) model which is also a world CGE model [42]. The simulations in the EPPA model use the Latin hypercube technique for analysing the impacts of 100 uncertain parameters, including labour productivity growth rates, energy efficiency trends, elasticities of substitution, costs of advanced technologies, fossil fuel resource availability and trends in emissions factors for urban pollutants. These simulations served to evaluate four climate policy scenarios and showed that energy demand parameters, including elasticities of substitution and energy efficiency trends, are the sources of uncertainty impacting more significantly climate policies. A previous study, also involving the EPPA model [41], focused on the uncertainty of the projections of anthropogenic emissions. It reported a range of temperature change in 2100 comprised between $0.9^{\circ} \mathrm{C}$ and $4.0^{\circ} \mathrm{C}$. In [36], MC simulations have been also performed on the integrated assessment model MiniCAM 1.0 to analyse the sources of uncertainty and their relative importance in the decision policy process. The paper concludes that the "current targets for atmospheric stabilization appear excessively ambitious" and that "an adaptive policy of 'act, then learn, then act' appears to offer better prospects for balancing uncertain costs and benefits of controlling greenhouse gas emissions than do rigid precautionary measures". More recently, MC simulations have been applied to the MERGE model [23] to produce probability distribution functions of economicand climate-related variables for different possible policies. Other references concerning MC simulations on global assessment models are given in [13, 30, 34].

In the present work, we identify four classes of uncertainties related to technology, economy, energy and climate, respectively. The first one regroups technological parameters, i.e. cost and date of availability of carbon capture and sequestration (CCS) technology, elasticities of substitution between energy forms and elasticities of substitution between production factors and technical progress factors. The second class deals with economic drivers such as GDP growth of emerging countries. The third one focuses on energy prices.
Finally, the last category, related to climate, is summarized by the Cs parameter. Recall that Cs is loosely defined as the temperature increase that would result from a doubling of atmospheric GHG concentration, compared with preindustrial level. So, in terms of climate policies, a variation in the assumed Cs value results in a different long-term GHG concentration target and, as a consequence, in a different profile for the emissions abatement schedule resulting from an adaptation of the global energy system. From a policy point of view, one has to formulate a hedging emission trajectory which will be implemented now and eventually corrected or adapted when a more precise knowledge of Cs is available. We assume that the uncertainty on Cs will be resolved in 2030, and we generate emission trajectories for different climate sensitivity values using the stochastic version of the model TIAM WORLD. By so doing, we get a single trajectory of emissions until 2030 and different profiles afterwards depending on the revealed climate sensitivity. GEMINI-E3 is run for an ensemble of scenarios corresponding to sampled values for all uncertain parameters. In the case of Cs, the sampled value will determine an emission profile after 2030, obtained by interpolation of the typical emissions trajectories produced by TIAM WORLD stochastic. The simulation results represented by the economic indicators, like, e.g. welfare loss, energy consumption and carbon price, are statistically analysed using logit and standard regression models. This permits an identification of the most sensitive parameters and of their role in the possible infeasibility of energy/climate policies.

The paper is organized as follows: In Section 2, we describe the specifications of the bottom-up TIAM WORLD and top-down GEMINI-E3 models used in this study. In Section 3, we model the different sources of uncertainty taken into consideration. In Section 4, we discuss the stochastic programming and MC implementation issues, and in Section 5, we analyse the simulation results. In conclusion, we evaluate the new insights brought by this analysis of uncertainty in a harmonized use of a bottom-up model (TIAM WORLD) and a topdown model (GEMINI-E3).

\section{The TIAM WORLD and GEMINI-E3 Models}

In this section, we give an overview of the two complementary models that are used for climate policy assessment. We also present the process of harmonization that has been implemented for the combined use of the two models. 


\subsection{Overview of TIAM WORLD}

\subsubsection{Energy/Technology/Emissions Description}

TIAM WORLD is a global technology-rich bottomup model that represents the entire energy system of the world divided in 16 regions: Africa, Australia-New Zealand, Canada, USA, Mexico, Central and South America, China, India, Japan, South Korea, other developing Asia, Middle East, EU30, other east Europe, Russia, Central Asia and Caucasia. It covers the procurement, transformation, trade and end-uses of all energy forms in all sectors of the economy (Fig. 1).

TIMES' economic paradigm is the computation of a dynamic inter-temporal partial equilibrium on energy/emission markets where demands for energy services are exogenously specified only in the reference case and are sensitive to price changes in alternate scenarios via a set of own-price elasticities at each period [25]. Although TIMES does not encompass all macroeconomic variables beyond the energy sector, accounting for price elasticity of demands captures a major element of feedback effects between the energy system and the economy. Thus, the equilibrium is driven by the maximization (via linear programming) of the discounted present value of total surplus, representing the sum of surplus of producers and consumers, which acts as a proxy for welfare in each region of the model.
The time horizon of TIAM WORLD extends to 2100. The model contains explicit descriptions of more than one thousand technologies and 100 commodities in each region, logically interrelated in a reference energy system [28]. Residential, commercial, industry, transport, power plants as well as upstream (from extraction to secondary transformation) are represented in a highly detailed mode, covering the 42 different service demands such as space heating, lighting, kilometres driven by cars, by buses, production of iron and steel, of pulp and paper etc. Such explicitness of the representation of technologies and fuels in all sectors allows precise tracking of capital turnover and provides a detailed description of technological competition and sectoral and cross-sectoral energy environmental policies.

\subsubsection{The Climate Module}

TIAM WORLD includes an endogenous climate module that allows the user to impose climate targets, such as upper bounds on concentrations, on atmospheric radiative forcing, or on temperature increase, at single or multiple dates. The emissions of $\mathrm{CO}_{2}, \mathrm{CH}_{4}$ and $\mathrm{N}_{2} \mathrm{O}$ related to the energy sector are explicitly represented by the energy technologies included in the model. The non-energy-related $\mathrm{CO}_{2}, \mathrm{CH}_{4}$ and $\mathrm{N}_{2} \mathrm{O}$ emissions (landfills, manure, rice paddies, enteric fermentation, wastewater, land-use) are also included in order to fully
Fig. 1 Reference energy system of TIAM WORLD

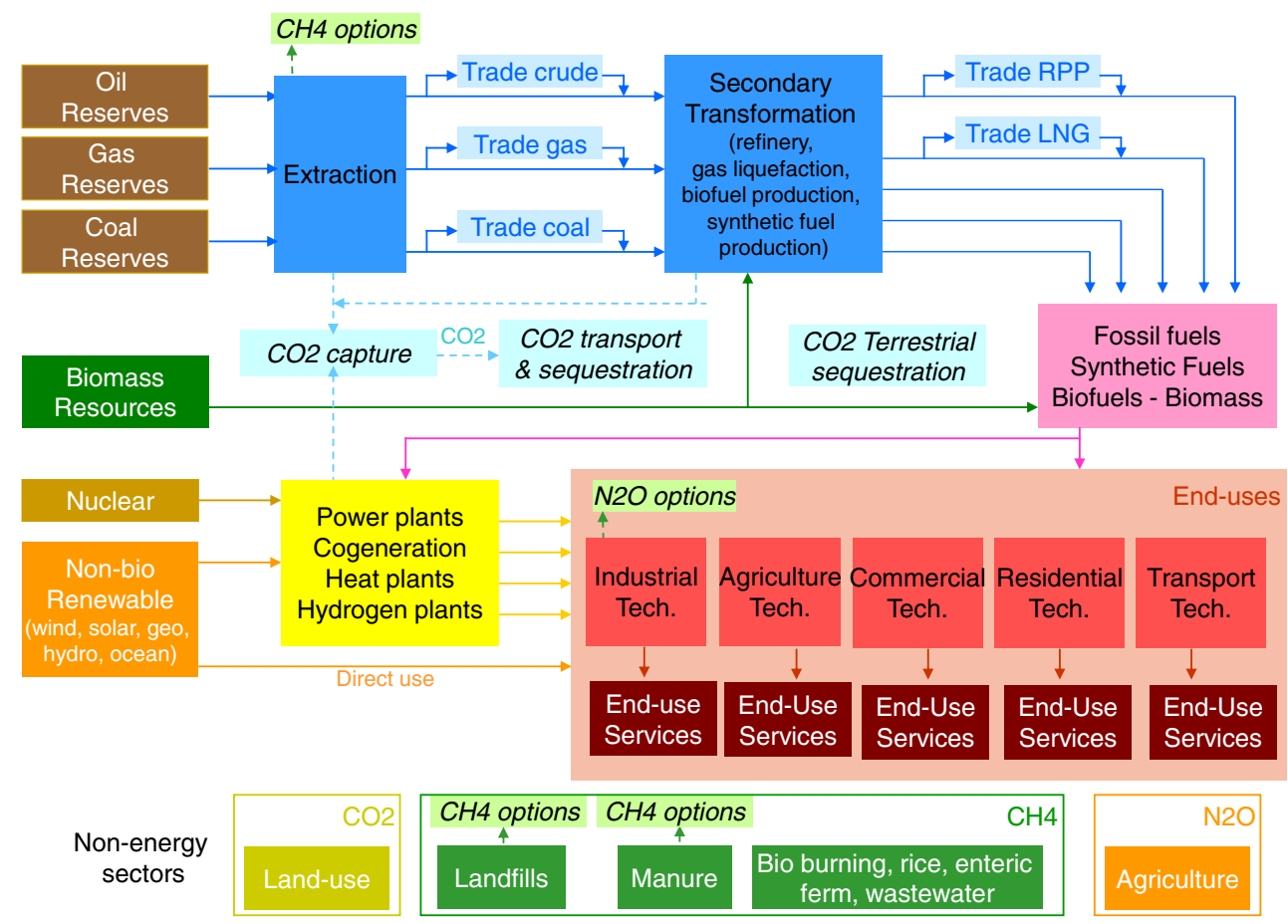


represent the radiative forcing induced by them, but they are exogenously defined. Emissions from some Kyoto gases (CFC's, HFC's, $\mathrm{SF}_{6}$ ) are not explicitly modelled, but a special radiative forcing term is added in the climate module. Emissions of chemically active gases such as NOx, CO, VOC's are not modelled either, but their influence on the life cycles of GHG gases is implicitly accounted for in the concentration equations for the three main GHG's, at the calibration phase of the equations.

Greenhouse gas mitigation options available in the model are energy substitutions, improved efficiency of installed devices, specific non- $\mathrm{CO}_{2}$ abatement devices (e.g. suppression and/or combustion of fugitive $\mathrm{CH}_{4}$ from landfills, thermal destruction of $\mathrm{N}_{2} \mathrm{O}$ in the adipic acid industry, suppression of leakages at natural gas transmission level, anaerobic digestion of wastes with gas recovery etc.), sequestration $\left(\mathrm{CO}_{2}\right.$ capture and underground storage, biological carbon sequestration), mitigation potential of up to $20 \%$ of the $\mathrm{CO}_{2}$ and $\mathrm{N}_{2} \mathrm{O}$ emitted by the agriculture sector and reductions in energy service demands in reaction to increased carbon prices.

\subsubsection{Stochastic TIAM WORLD}

TIAM WORLD possesses a feature that allows the modeller to calculate hedging strategies in the presence of uncertainty for certain key parameters. The treatment of uncertainty is done via stochastic programming in extensive form. In this method, the model adopts a single hedging route in the interval of time preceding the resolution of uncertainty (act then learn), so as to be best positioned to adapt to any of the possible long-term futures (after resolution of uncertainty). In a large-scale model such as TIAM WORLD, due to computational considerations, the stochastic programming approach is successful when the uncertain parameters are assumed to have only a limited number of possible outcomes. The uncertainty is therefore described via an event tree with a reasonably small number of endpoints. Finally, in our application, the selected maximization criterion is the expected value of the total surplus, but the approach is also valid with other criteria, such as minimizing the savage criterion (MinMax Regret), as in [27], or a utility function consisting of a linear combination of expected surplus minus a quantity representing risk (see the TIMES documentation available at www.etsap.org/documentation).

The main interest of a hedging strategy resides in its description of what to do prior to the resolution date (in contrast, traditional deterministic scenario analysis computes multiple strategies even prior to the resolu- tion date, leaving the decision maker in a quandary). Once uncertainty is resolved, the decision maker no longer faces uncertainty and her decisions result from optimizing a deterministic problem afterwards. Nevertheless, the computation of the hedging strategy must also take into account all possible outcomes after the resolution date. In other words, short-term decisions are devised while taking the uncertain long term into consideration. This is the essence of decision under risk and in particular of stochastic programming.

The TIAM WORLD model in stochastic mode was used to model a number of energy and environmental issues [22, 24, 29], with uncertainty assumed on economic parameters and/or on climate parameters.

\subsection{Overview of GEMINI-E3}

GEMINI-E3 ${ }^{1}$ is a multi-country, multi-sector, recursive computable general equilibrium model comparable to the other CGE models (GREEN, EPPA, MERGE, Linkage, WorldScan) built and implemented by other modelling teams and institutions and sharing the same long experience in the design of this class of economic models. The standard model is based on the assumption of total flexibility in all markets, both macroeconomic markets such as the capital and the exchange markets (with the associated prices being the real rate of interest and the real exchange rate, which are then endogenous) and microeconomic or sector markets (goods, factors of production) (Table 1$)$.

The model is built on a comprehensive energyeconomy dataset, the GTAP-6 database [12], that incorporates a consistent representation of energy markets in physical units, social accounting matrices for each individualized country/region and the whole set of bilateral trade flows. Additional statistical information accrues from OECD national accounts, IEA energy balances and energy prices/taxes and IMF Statistics (government budget for non-OECD countries). Carbon emissions are computed on the basis of fossil fuel energy consumption in physical units. For the modelling of non- $\mathrm{CO}_{2}$ greenhouse gases emissions $\left(\mathrm{CH}_{4}\right.$, $\mathrm{N}_{2} \mathrm{O}$ and F-gases), we employ region- and sectorspecific marginal abatement cost curves and emission projections provided by the Energy Modeling Forum within the Working Group 21 [40].

For each sector, the model computes the demand on the basis of household consumption, government con-

\footnotetext{
${ }^{1}$ The Web site http://gemini-e3.epfl.ch/ provides all information about the model, including its complete description.
} 
Table 1 Dimensions of the GEMINI-E3 model

\begin{tabular}{|c|c|c|}
\hline \multicolumn{2}{|l|}{ Countries or regions } & \multirow{2}{*}{$\begin{array}{l}\text { Sectors } \\
\text { Energy }\end{array}$} \\
\hline$\overline{A n n e x ~ B ~}$ & & \\
\hline Germany & DEU & 01 Coal \\
\hline France & FRA & 02 Crude oil \\
\hline United Kingdom & GBR & 03 Natural gas \\
\hline Italy & ITA & 04 Refined petroleum \\
\hline Spain & ESP & 05 Electricity \\
\hline Netherlands & NLD & Non-energy \\
\hline Belgium & BEL & 06 Agriculture \\
\hline Poland & POL & 07 Forestry \\
\hline Rest of EU-25 & OEU & 08 Mineral products \\
\hline Switzerland & $\mathrm{CHE}$ & 09 Chemical rubber plastic \\
\hline Other European countries & XEU & 10 Metal and metal products \\
\hline United States of America & USA & 11 Paper products publishing \\
\hline Canada & CAN & 12 Transport n.e.c. \\
\hline Australia and New Zealand & AUZ & 13 Sea transport \\
\hline Japan & JAP & 14 Air transport \\
\hline Russia & RUS & 15 Consuming goods \\
\hline Rest of Former Soviet Union & XSU & 16 Equipment goods \\
\hline Non-annex B & & 17 Services \\
\hline China & $\mathrm{CHI}$ & 18 Dwellings \\
\hline Brazil & BRA & \\
\hline India & IND & Household sector \\
\hline Mexico & MEX & \\
\hline Venezuela & VEN & Primary factors \\
\hline Rest of Latin America & LAT & Labour \\
\hline Turkey & TUR & Capital \\
\hline Rest of Asia & ASI & Energy \\
\hline Middle East & MID & Fixed factor (sectors 01-03) \\
\hline Tunisia & TUN & Other inputs \\
\hline Rest of Africa & AFR & \\
\hline
\end{tabular}

sumption, exports, investment and intermediate uses. Total demand is then divided between domestic production and imports, using the Armington assumption [3]. Under this convention, a domestically produced good is treated as a different commodity from an imported good produced in the same industry. Production technologies are described using nested CES functions (see Fig. 5).

Time periods are linked in the model through endogenous real rates of interest determined by equilibrium between savings and investment. National and regional models are linked by endogenous real exchange rates resulting from constraints on foreign trade deficits or surpluses. The main outputs of the GEMINI-E3 model are by country on an annual basis: carbon taxes, marginal abatement costs and prices of tradable permits (when relevant), effective abatement of $\mathrm{CO}_{2}$ emissions, net sales of tradable permits (when relevant), total net welfare loss and components (net loss from terms of trade, pure deadweight loss of taxation, net purchases of tradable permits when relevant), macroeconomic aggregates (e.g. production, imports and final demand), real exchange rates and real interest rates and data at the industry level (e.g. change in production and in factors of production, prices of goods).

Like other general equilibrium models, GEMINIE3 assesses the welfare cost of policies through the measurement of the classical Dupuit's surplus, i.e. in its modern formulation the equivalent variation of income or the compensating variation of income. It is commonly acknowledged that surplus is preferable to change in GDP or change in households' final consumption because these aggregates are measured at constant prices according to the methods of national accounting and do not capture the change in the structure of prices, a main effect of climate change policies [7]. Moreover, it is revealing to split the welfare cost between its two components, the domestic component or deadweight loss of taxation and the imported component or gains from terms of trade.

\subsubsection{Aggregate Version of GEMINI-E3 Used in This Study}

The classifications-breakdowns by country/region and by sector/product—are framed according to the general 
Fig. 2 Nesting CES structure of electricity production

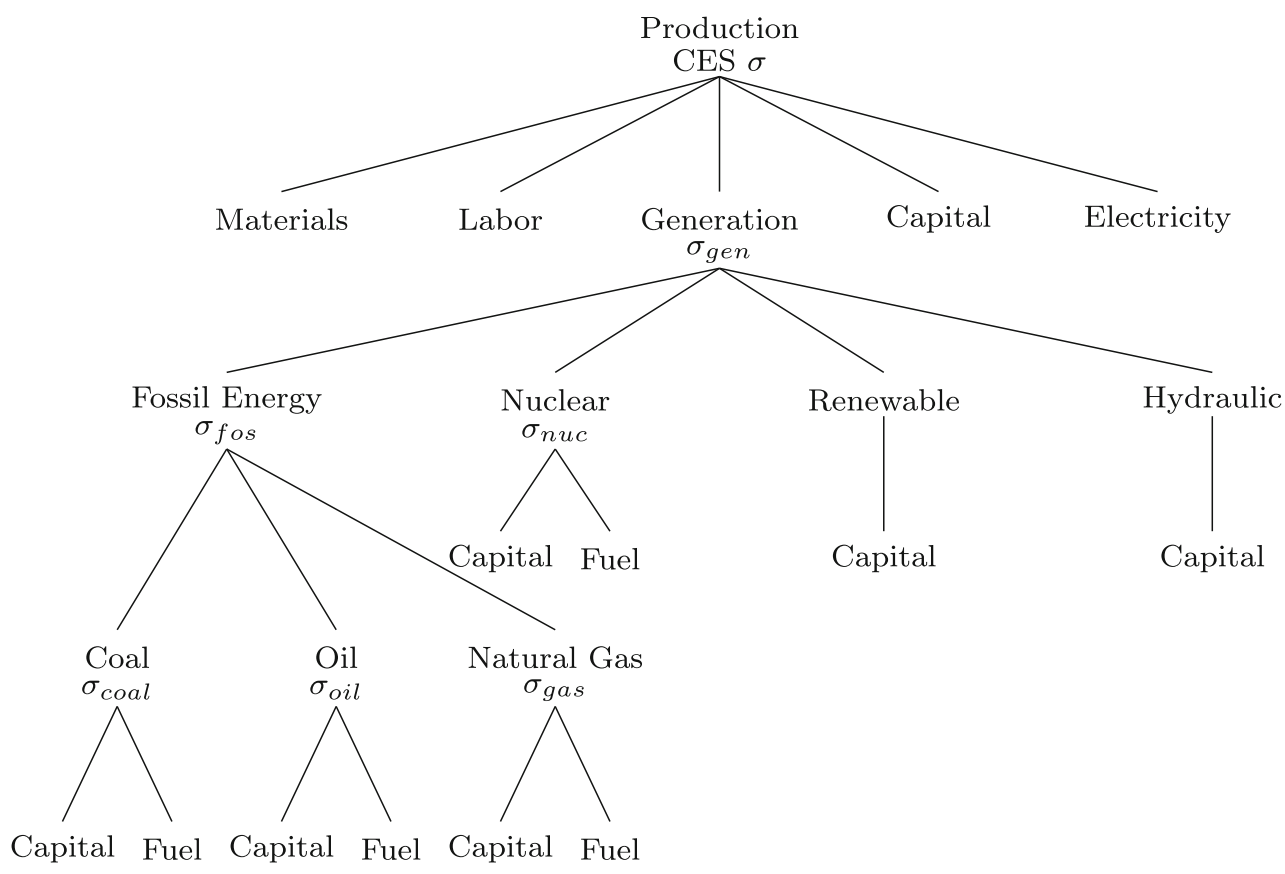

context and the targets of each study. An important issue applying Monte Carlo simulations is to make the procedure consistent with respect to the uncertainty. One may produce a set of scenarios large enough to be representative of all possible realizations so that the result interpretations are well founded. Thus, in order to perform a high number of Monte Carlo simulations in a reasonable CPU time, we use an aggregate version of GEMINI-E3. We use the following reduced classification:

\section{EUR European Union}

OEC Other developed countries

EEC Oil exporting countries (Middle East and Former Soviet Union)

ASI Asian countries

ROW Rest of the world

Using this classification, the CPU time for one run of GEMINI-E3 is about $5 \mathrm{~min}^{2}$

\subsubsection{Modelling Power Generation in GEMINI-E3}

In order to reliably model the role of CCS in power generation, electricity production is now represented by a nested CES function including-besides fossil fuels, nuclear and hydraulic plants-the new capacities installed in the renewable technologies, as shown in Fig. 2. Then power generation is separated from the

\footnotetext{
${ }^{2}$ We used a Dual 2.6-GHz Intel Xeon computer for the simula-
} tions; thus, we had four available CPUs. other activities (transmission and distribution) that appear through their factors of production at the top of the nesting structure. Power generation involves only two factors of production, capital and fuel (only capital for renewables). ${ }^{3}$ Concerning CCS, we suppose that this technology could only be used with coal and CCS is implemented when the cost of carbon per ton sequestered is inferior to the price of carbon computed by the model at equilibrium. The cost of CCS is described in Section 3.2.1. With this new nesting structure, it is possible to better take into account the power generation portfolio and to represent inter-fuel substitutability as well as substitutability between fossil and renewable power generation [43]. This representation does not distinguish between base and peak production which will be only possible by representing differentiated demands. We approximate the fact that nuclear, renewable and fossil fuel are not completely substitutable by using different elasticity parameters with the assumption that $\sigma_{\text {fos }}>\sigma_{\text {gen }}$. We assume no constraint on the deployment of nuclear and renewable due for example to political acceptability.

\subsubsection{GDP Growth Assumptions}

Reference scenarios in CGE models are built from forecasts or assumptions on economic growth in

${ }^{3}$ Labour in the generation activity is low compared to labour in the other activities (transport, distribution) and of a similar relative size for all plants. It is thus represented as a common factor. 
Table 2 GDP Growth in percentage per year

\begin{tabular}{lcccc}
\hline & $\begin{array}{l}2010-2020 \\
(\%)\end{array}$ & $\begin{array}{l}2020-2030 \\
(\%)\end{array}$ & $\begin{array}{l}2030-2040 \\
(\%)\end{array}$ & $\begin{array}{l}\text { 2040-2050 } \\
(\%)\end{array}$ \\
\hline EUR & 2.3 & 1.8 & 1.4 & 1.4 \\
OEC & 2.4 & 1.9 & 1.9 & 2.0 \\
EEC & 3.7 & 3.0 & 2.1 & 1.9 \\
ASI & 5.5 & 4.3 & 2.9 & 3.0 \\
ROW & 4.5 & 3.4 & 2.6 & 2.6 \\
World & 3.2 & 2.6 & 2.2 & 2.2 \\
\hline
\end{tabular}

the various countries/regions and national (energy) policies. Assumptions concerning GDP growth are consistent with the World Energy Technology Outlook done by the European Commission ${ }^{4}$ [16]. Table 2 summarizes the projected annual GDP growth for each region. The world GDP growth will converge in 2050 to $2.2 \%$ per year. The growth would be greater in developing and emerging countries.

\subsection{Harmonization of the Two Models}

In this paper, we used a harmonized version of the models TIAM WORLD and GEMINI-E3, and both models are run independently except that in the "policy" scenarios the climate target is given by TIAM WORLD. Through harmonization, we ensure that certain key assumptions shared between models are consistent. The first common assumption is linked to economic growth. We use the same demographic assumptions and GDP growth by region, and the energy service demands of TIAM WORLD are computed using drivers provided by GEMINI-E3. These drivers in the TIAM WORLD model are related to household consumption and industrial outputs (cement, iron and steel productions etc.) which are directly computed by GEMINI-E3. A similar procedure is done concerning energy prices. In this paper, the energy prices are given exogenously to both models (see Section 3.4). Finally, we use the same assumptions about the costs of CCS (which is also given exogenously see Section 3.2.1), and we ensure that the costs of electricity generation are consistent across technologies. This harmonization is only done for the business as usual (BAU) scenario, whereas in the climate policy scenarios, the only link between the two models is the GHG target which is computed on the basis of TIAM WORLD simulations.

\footnotetext{
${ }^{4}$ Note that these assumptions, imposed under the FP7 European project Planets, lead to lower GDP growth than those of the most recent forecasts [15] that incorporate the impact of the current economic crisis. This low GDP growth is primarily due to the conservative growth assumptions for developing countries and especially Asia. This source of uncertainty is discussed in Section 3.3.
}

\section{Uncertainties}

In this section, we describe the uncertain parameters taken into consideration, and we give the assumptions on probability distributions that are used to generate the ensemble of scenarios via a Latin hypercube method. We classify the uncertain parameters in four main categories: climate, technology, economy and energy prices.

\subsection{Climate Uncertainty}

Climate modelling is based on a set of critical physical and technical parameters. Among these parameters, Cs is one of the most important. Its assumed value influences strongly the temperature increase projections computed by climate models and at the same time Cs is highly uncertain. We suppose, as often assumed in similar studies that Cs uncertainty will be resolved in the future, ${ }^{5}$ around 2030. Therefore, our approach is two-phased and combines optimal hedging computations and MC simulations.

In the first phase, we use the stochastic version of the energy-economy model TIAM WORLD to generate a hedging strategy from 2005 to 2030, followed by contingent optimal recourse strategies after 2030. The uncertainty on Cs is thus represented by a simple event tree representing a discrete approximation of the Cs probability distribution. Ideally, we would want to run TIAM WORLD under a very detailed event tree on Cs, in order to better approximate its continuous pdf. This would produce a single hedging decision before the resolution date (e.g. until 2030) and a large number of subsequent recourse abatement scenarios on all the branches of the event tree after that date. Then, GEMINI-E3 would be run using directly the emission profiles obtained from TIAM WORLD results.

In practice, this approach is not computationally feasible since the stochastic program resulting from a very detailed event tree would create too large an instance of TIAM WORLD, the model becoming then computationally intractable. Therefore, we discretized the pdf of Cs and created an event tree with four branches corresponding to $\mathrm{Cs}$ values $1.1^{\circ} \mathrm{C}, 1.7^{\circ} \mathrm{C}, 2.9^{\circ} \mathrm{C}$ and $4.4^{\circ} \mathrm{C}$. The choice of the continuous distribution and the discretization issue are detailed in Section 4.1. By running TIAM WORLD in its stochastic programming version with this reduced event tree, we obtain a single

\footnotetext{
${ }^{5}$ Some recent publications $[1,35]$ tend to affirm that it might be impossible to resolve uncertainty about $\mathrm{Cs}$ in the foreseeable future. If this is the case, the decision in 2030 should be based on the worst-case alternative.
} 
Table 3 Emission trajectories from TIAM WORLD stochastic runs (in Gt of C-eq)

\begin{tabular}{lllrrrr}
\hline & 2005 & 2010 & 2020 & 2030 & 2040 & 2050 \\
\hline $\mathrm{Cs}=1.1$ & 10.19 & 10.46 & 9.09 & 9.62 & 15.38 & 19.20 \\
$\mathrm{Cs}=1.7$ & 10.19 & 10.46 & 9.09 & 9.62 & 15.11 & 18.60 \\
$\mathrm{Cs}=2.9$ & 10.19 & 10.46 & 9.09 & 9.62 & 11.75 & 11.96 \\
$\mathrm{Cs}=4.4$ & 10.19 & 10.46 & 9.09 & 9.62 & 5.39 & 3.17 \\
$\mathrm{Cs}=2.9$ (det.) & 10.19 & 10.46 & 11.62 & 11.99 & 11.22 & 10.55 \\
\hline
\end{tabular}

hedging emission profile until 2030 and four recourse policies after 2030, each one corresponding to a typical Cs value. The four resulting emission trajectories (in Gt of carbon-equivalent) are reported in Table 3 and plotted in Fig. 3. We also indicate in Table 3 and in Fig. 3 the emission trajectories resulting from the deterministic version of TIAM WORLD with a Cs value ${ }^{6}$ of 2.9.

In the second phase, we exploit those four emission trajectories obtained from TIAM WORLD in the Monte Carlo simulations. Using Latin hypercube technique, we generate a large random sample of 2000 values for the driving parameters of GEMINI-E3. Among these parameters are Cs values which are sampled from a triangular distribution in the interval [1.1, 4.4] with mode 2.9 (see Fig. 4). For each sampled Cs value, we use linear interpolation of the two adjacent typical values treated in TIAM WORLD to get a sample emission trajectory. In the corresponding simulation, GEMINIE3 uses this emission trajectory as the imposed climate policy after 2030.

The comparison of the emission trajectories of the deterministic and the stochastic scenarios assuming the same Cs value of 2.9 is quite instructive. In the deterministic case, the planner acts as if one knows with certainty that the Cs value is 2.9. This is a relatively low value, and therefore, the emissions need not decrease rapidly until around 2030 . In the stochastic case, the policy maker does not have this knowledge until year 2030 and therefore must hedge against all possible values of $\mathrm{Cs}$, including the large value $\mathrm{Cs}=4.4$, and this induces the model to decrease emissions much earlier (i.e. before the resolution date of 2030), in order to be positioned for any future possibility. At year 2030, still in the stochastic scenario, the true value of Cs is revealed, and if Cs happens to be equal to 2.9, the future emissions need not be as small as in the deterministic case. This crossing over of the two trajectories is quite evident in Fig. 3 for $\mathrm{CO}_{2}$ emissions and less pronounced for the other two greenhouse gases. In the experiments, we use this deterministic run to contrast and discuss the stochastic results.

\footnotetext{
${ }^{6}$ Note that the IPCC AR4 best estimate is 3 .
}

\subsection{Technological Uncertainties}

\subsubsection{Carbon Capture and Sequestration}

In several recent studies (e.g. [31, 32]), the implementation of CCS technologies appears as a key element of cost-effective GHG abatement policies. In [31], the authors show that it is possible for the European electricity generation system to cut $85 \%$ of $\mathrm{CO}_{2}$ emissions by 2050 when CCS penetrates significantly after 2020. In TIAM WORLD scenarios corresponding to severe climate constraints, CCS technologies are used for electricity production and transport fuel production (hydrogen, biodiesel, alcohols, Fischer-Tropps, from coal or biomass).

However, the deployment and the commercial availability of these technologies are still uncertain. As in $[31,32]$, we assume in the CGE that CCS technologies will be available in the future (e.g. between 2020 and 2050) only in the electricity production sector (coal based production) with uncertain parameters concerning capture, transportation and sequestration costs and date of commercial availability.

As discussed in the technical report, ${ }^{7}$ [20] we retained two contrasted scenarios for the CCS deployment, combined with high-cost vs. low-cost scenario. In the first deployment scenario, CCS is available in 2020 and we assume the costs as reported in Table 4. In the second scenario, CCS is commercially available in 2030 only, and the costs are the same as in the previous scenario, but with year shifted 10 years on. To simulate CCS cost trajectories for the stochastic analysis, we first assume that the two above cost development scenarios are equiprobable, and for each time period, we straightforwardly deduce from the figures in Table 4 a range of possible realizations for the total CCS costs that is the sum of transport, storage and capture costs. For example, the total cost in 2020 for the first scenario will take values within the interval $[15+10+25,20+10+$ $50]=[50,80]$. Finally, we generate a cost trajectory by sampling uniformly a unique random factor between 0

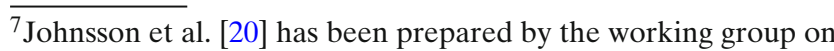
the technology assessment of the PLANETS EU-project.
} 


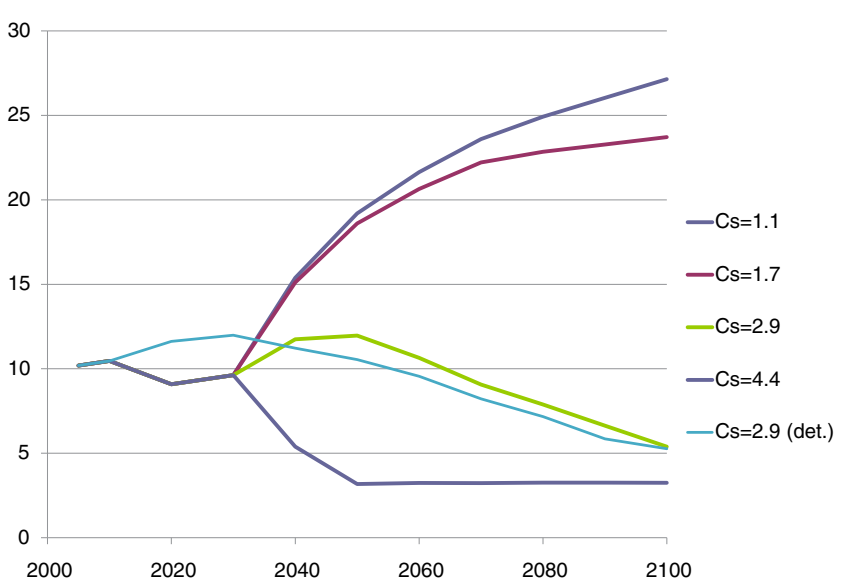

Fig. 3 Emission trajectories from TIAM WORLD stochastic runs (in Gt of C-eq)

and 1 that will be used for all periods to make linear interpolation in the above-defined cost intervals.

\subsubsection{Energy Efficiency Improvement}

As most models used to assess climate change policies, GEMINI-E3 assumes an exogenous rate of energy efficiency improvement called "autonomous energy efficiency improvement" (AEEI) [5, 17]. This AEEI handles the historical trend of efficiency improvement that is independent of economic changes such that, e.g. energy prices or economic growth. In GEMINIE3, the AEEI lies in the range of $1-2.2 \%$ per year depending on time periods, regions and sectors. We assume a normal distribution, normalized to a mean of 1.0 and a standard deviation of 0.4 , and apply the

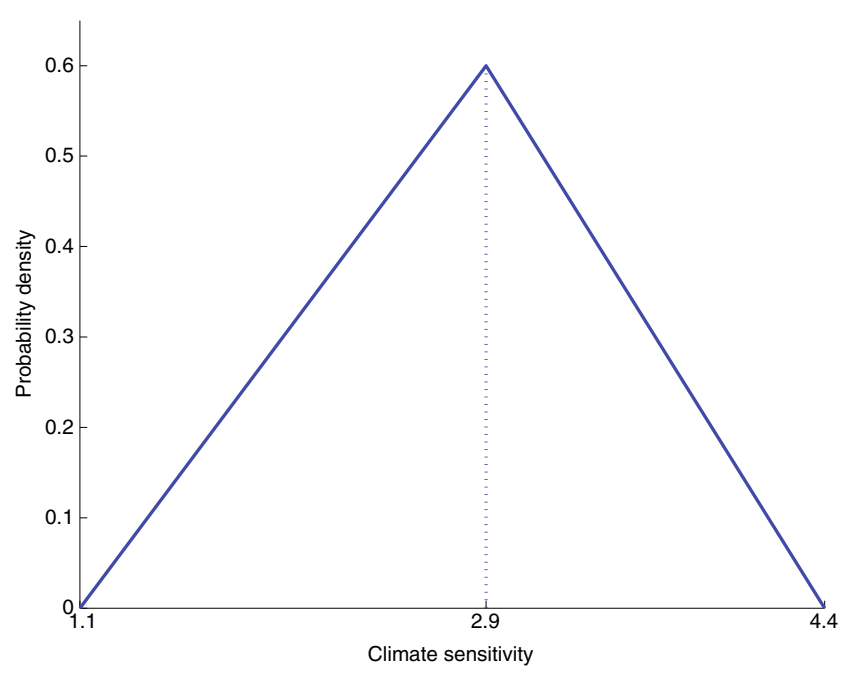

Fig. 4 Triangular probability density function
Table 4 Cost development scenario for transport, storage and capture in $€ /$ ton of $\mathrm{CO}_{2}$

\begin{tabular}{lrrrr}
\hline Year & $\begin{array}{r}\text { Transport } \\
\text { (high/low) }\end{array}$ & Storage & $\begin{array}{l}\text { Capture } \\
\text { (high/low) }\end{array}$ & $\begin{array}{l}\text { Total } \\
\text { (high/low) }\end{array}$ \\
\hline 2020 & $20 / 15$ & 10 & $50 / 25$ & $80 / 50$ \\
2025 & $10 / 7$ & 7 & $40 / 20$ & $57 / 34$ \\
2030 & $5 / 5$ & 5 & $37.5 / 17.5$ & $47.5 / 27.5$ \\
2035 & $3.5 / 3$ & 3.5 & $35 / 15$ & $42 / 21.5$ \\
\hline
\end{tabular}

positive sampled value as a multiplicative factor for the regionally and time varying AEEIs as specified in GEMINI-E3. Note that this standard deviation is similar to that retained by [42].

\subsubsection{Elasticities of Substitution}

Production is represented in GEMINI-E3 through nested CES functions as shown in Fig. 5. We assume that the possibilities of substitution are identical between countries for a given sector, but differ between sectors. We focus our analysis on three elasticities which play a central role in energy consumption in the GEMINI-E3 model:

- The elasticity between aggregate inputs (i.e. the elasticity between materials, energy, labour and capital, represented in Fig. 5 by $\sigma$ )

- The elasticity between electricity and fossil fuel energy $\left(\sigma_{\mathrm{e}}\right)$

- The elasticity between fossil fuel energies $\left(\sigma_{\mathrm{ef}}\right)$

In a certain sense, the elasticity of substitution can serve as an indicator of technological "flexibility". For these three parameters, we retain two multiplicative

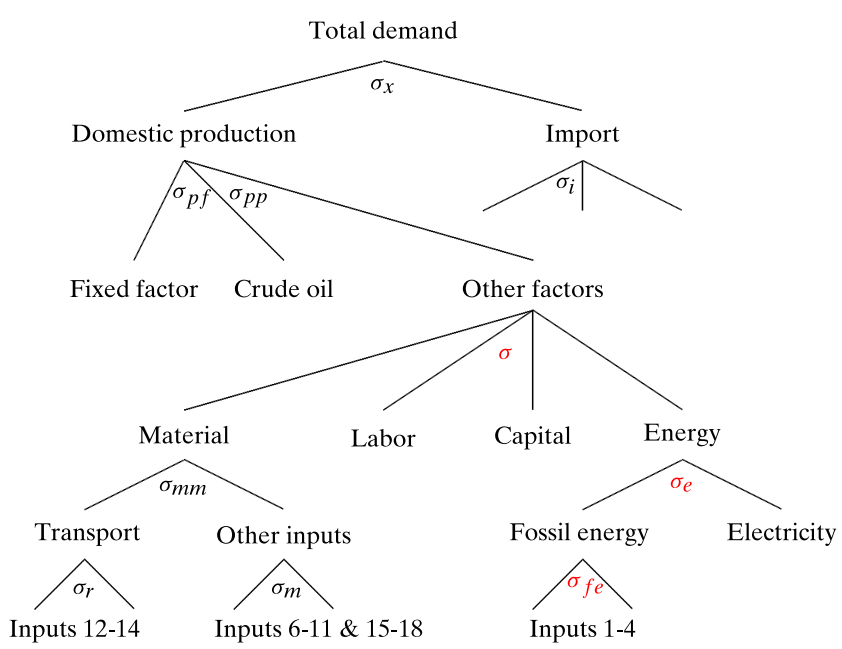

Fig. 5 Nesting CES structure of production in GEMINI-E3 
Table 5 Mean and standard deviation of historical per-capita GDP growth rates 1950-2000 (source: [42])

\begin{tabular}{lcc}
\hline Region & Mean & $\begin{array}{c}\text { Standard } \\
\text { deviation }(\%)\end{array}$ \\
\hline USA & 2.2 & 2.3 \\
Canada & 2.3 & 2.3 \\
Mexico & 2.2 & 5.2 \\
Japan & 4.9 & 3.5 \\
Australia and New Zealand & 2.0 & 1.8 \\
European Union & 2.8 & 1.6 \\
Eastern Europe & 1.1 & 3.9 \\
Former Soviet Union & 1.1 & 5.3 \\
East Asia & 4.3 & 4.7 \\
China & 4.3 & 3.7 \\
India & 2.3 & 2.7 \\
Indonesia & 2.7 & 5.0 \\
Africa & 1.0 & 1.8 \\
Middle East & 2.3 & 3.3 \\
Central and South America & 1.7 & 2.0 \\
Rest of the world & 2.2 & 3.5 \\
\hline
\end{tabular}

random factors, one for $\sigma$ and the other for $\sigma_{\mathrm{e}}$ and $\sigma_{\mathrm{ef}}$. The two factors have a normal distribution, normalized to a mean of 1.0 and a standard deviation of 0.3 . This assumption is in line with the standard deviation estimated in [39] and used in simulations of the EPPA model [42].

\subsection{Economic Growth Uncertainty}

On the basis of the historical per-capita GDP growth rates computed by [42] (see Table 5), we find that the variance of this variable is greater in developing countries and lower in developed countries. Moreover, the per-capita GDP growth is much higher in developing countries, and the implications of this uncertainty are in consequence particularly important on the world GDP growth. In contrary, the uncertainty concerning the population growth seems not really different between these two regions, if we compare the world population prospects done by the United Nation [38] among the different assumptions used (i.e. fertility, mortality and international migration). Consequently, we suppose that the main uncertainty concerning the GDP growth is located in developing countries, and this means in our regional classification ASI and the ROW. In a CGE like GEMINI-E3, the economic growth is derived from the growth of production factors (labour, capital, energy) and from the technical progress associated to each factor. ${ }^{8}$ Among them, the most important factors are the growth of labour force and the evolution of labour

\footnotetext{
${ }^{8}$ Note that we take an uncertainty on the technical progress associated to energy, see Section 3.2.2.
}

productivity. The technical progress associated to each factor is calibrated in this study in order to reproduce an economic growth and energy consumptions consistent with the World Energy Technology Outlook done by the European Commission [16]. We retain the same assumption concerning the growth of labour force in all scenarios (i.e. stochastic runs) based on the median variant of the United Nation, but we use different technical progress associated to labour in ASI and ROW to represent the uncertainty surrounding the economic growth of these two regions. For these productivity factors, we use two different multiplicative random factors having a normal distribution, normalized to a mean of 1 and with a standard deviation equal to $30 \%$. We suppose also that these two technical progress are correlated with a correlation ratio equal to 0.5 , and a similar assumption is also adopted in [42].

\subsection{Oil and Gas Price Uncertainty}

Oil price is highly volatile and has an important impact on economy [33] (for example, it varied quickly between $\$ 40$ and $\$ 140$ between July 2008 and December 2008). The uncertainty related to oil price raises thus a challenging issue. In the long term, oil price will be affected by several factors, among which are the development of oil reserves, the arrival of new extraction techniques, the behaviour of oil producers (OPEC), the emergence of unconventional oil, changes in demand etc. In the last International Energy Outlook [14], the US Department of Energy summarized this uncertainty by choosing three alternative oil price cases which are displayed on Fig. 6:

- In the reference case, world oil price (in real 2007 dollars) rises from $\$ 68$ per barrel in 2006 to $\$ 130$ per barrel in 2030 .

- In the high price case, world oil price climbs to $\$ 200$ per barrel in 2030 .

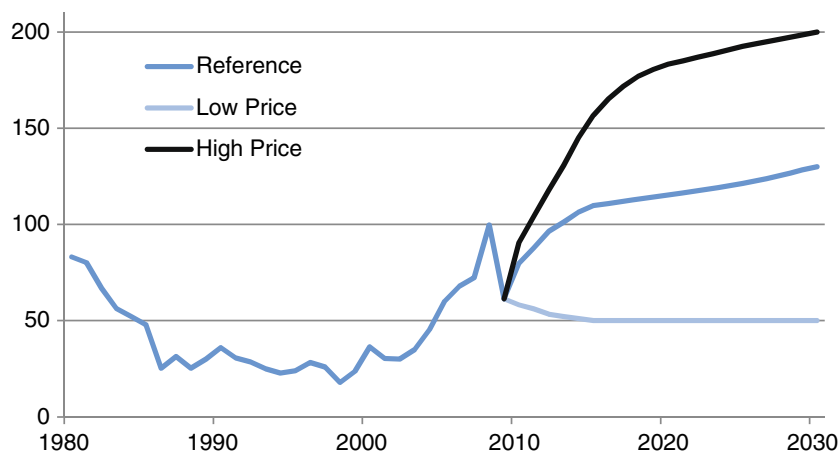

Fig. 6 World oil price in International Energy Outlook 2009 in 2007 dollars per barrel [14] 
- In the low price case, it declines to $\$ 50$ per barrel in 2015 and remains at that level through 2030.

To model the uncertainty of oil price, we use a normal distribution with average value of $100 \$$ and a coefficient of variation of $25 \%$ to ensure a $95 \%$ confidence interval $[50,150]$. We assume that this price is reached in 2015 and then remains constant throughout the duration of the simulation in real value. This assumption is in line with the DOE scenarios and based on a panel experts review of the FP7 EU Project PLANETS.

Natural gas price is strongly related to oil price and several studies point out this relation. Siliverstovs et al. [37] analyse the market integration for natural gas and the link between oil price and gas price, and their conclusions differ according to regions. They find that following the liberalization of the US market, a decoupling of natural gas prices and oil prices occurred. For the European market, there is in contrary a strong evidence for cointegration between the oil price brent and European gas price. In Asia, the price indexation of natural gas refers to blend of different crude oils. Awerbuch and Sauter [4] have estimated the oil-gas price correlation for the 1973-2003. They find that the long-term oil-gas correlations for the USA and EU are in range of 0.7 and that this indexation becomes higher for more recent periods. Several factors explain this relationship. At the demand side, natural gas and oil products are substitutes in consumption (especially for electricity generation and industrial process), and an increase of crude oil price will increase the gas demand and so its price. At the supply side, natural gas is often produced as a co-product of oil, and longterm contracts of imported gas retain indexation rules on oil price. According to these studies, we assume an indexation of gas prices to the price of oil at 0.75 (i.e. the price of gas increases by $7.5 \%$ when the oil price increases by $10 \%$ ). For coal prices, we do not introduce any uncertainty parameter, and the price is based on the figures computed by the TIAM WORLD for the BAU scenario. Note that these assumptions concerning energy prices are only introduced in the BAU scenarios; in practical terms, we calibrate the supply curves of the energy sector (oil, natural gas and coal) in order to reproduce these energy prices. In the climate policy scenarios, we let the GEMINI-E3 model compute these energy prices endogenously on the basis of supplydemand equilibrium. Thus, in the case of ambitious climate policy, the decline in fossil fuel consumption leads to a decrease of energy prices.

There is an extensive theoretical and empirical literature on the macroeconomic effects of oil price shocks

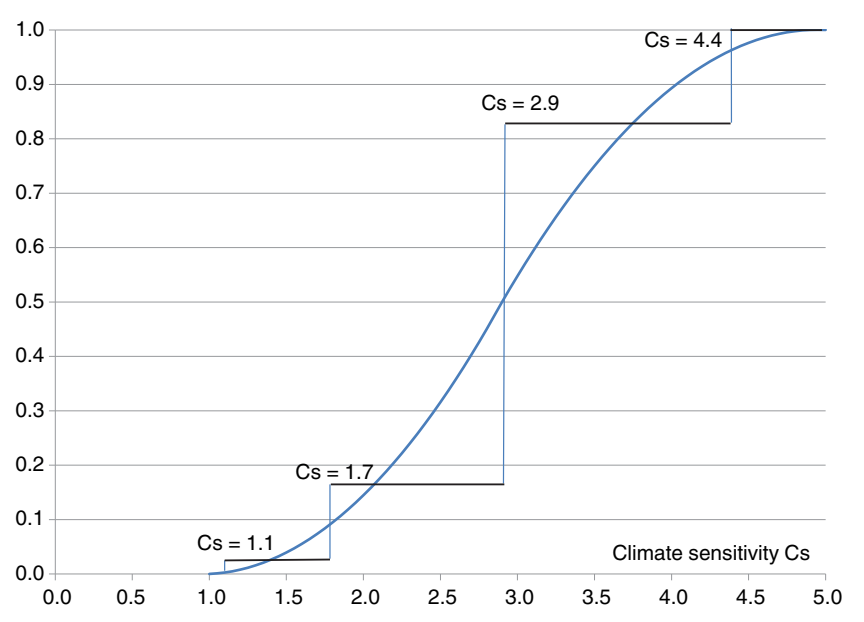

Fig. 7 Unbiased discrete pdf of Cs

[21]. Barsky and Kilian [6] identify a number of mechanisms that might provide a causal link from oil prices to recessions, inflation and economic growth. However, in a more recent paper, Blanchard and Gal [9] find that the impacts of oil price shocks have changed over time, with steadily smaller effects on output. For the sake of simplicity, we do not consider in this paper any correlation between energy price and economic growth, and the two uncertainties are assumed to be independent.

\section{Implementation Issues}

\subsection{TIAM WORLD Stochastic for Generating Optimal Hedging Strategies}

The stochastic version of the energy economy model TIAM WORLD [24] is used in the first phase of the procedure described in Section 3.1 for generating hedging strategies for different Cs factors. The first concern of this phase is the choice of an appropriate continuous probability distribution to represent the uncertainty of Cs. We have selected a triangular distribution on the interval $[1,5]$ and with mode 2.9 . This choice is motivated by the observations that the mode 2.9 and the minimum value of 1 are generally accepted in the literature [19]. Its maximum value is a controversial matter in the literature. The proposed values are often between 4 and

Table 6 Discrete distribution of probability for climate sensitivity

\begin{tabular}{lc}
\hline Cs & Probability \\
\hline 1.1 & 0.01 \\
1.7 & 0.15 \\
2.9 & 0.66 \\
4.4 & 0.18 \\
\hline
\end{tabular}


Table 7 The set of quotas used for the policy scenario

\begin{tabular}{llcc}
\hline Regions & Starting date of quotas & $\begin{array}{l}\text { Quotas in 2050 wrt 2005 } \\
\text { (reduction in brackets) }\end{array}$ & $\begin{array}{l}\text { Share of quotas } \\
(\%)\end{array}$ \\
\hline EUR & 2015 & $10 \%$ (reduction $=90 \%)$ & 7 \\
OEC & 2015 & $10 \%$ (reduction $=90 \%)$ & 16 \\
ASI & 2025 & $100 \%$ (reduction $=0 \%)$ & 40 \\
EEC & 2025 & $100 \%$ (reduction $=0 \%)$ & 16 \\
ROW & 2025 & $200 \%$ (reduction $=100 \%)$ & 21 \\
Sum & & & 100 \\
\hline
\end{tabular}

9, some studies proposing even larger maximum values. In the present study, we choose the value 5 for technical considerations, since we have observed that GEMINIE3 does not produce reasonable solutions for larger values. Given those parameters (mode and range), we also have observed that the impacts of the distribution on the TIAM WORLD results are negligible.

The second issue to be resolved concerns the discretization of the triangular distribution. To limit the size of the stochastic programming model, we shall use a four-branch event-tree. The choice of the discrete values for Cs must satisfy two conflicting conditions. First, the discrete probability distribution must be an unbiased approximation of the continuous pdf, but second, the discrete Cs values must encompass most (or all) the true range of possible Cs values. These two conditions are indeed conflicting because if we choose a broad range for the discrete Cs values (so as to satisfy the second condition), the two extreme values (the lowest and the largest) will not be representative of the continuous pdf, thus violating the first condition.

In conclusion, we should choose the lowest discrete value to be sufficiently larger than 1 , in order to attribute to it a non-zero probability. We propose Cs = 1.1 (see Fig. 7). In Fig. 7, the discrete value Cs $=1.1$ is an unbiased representative of the range extending from 1 to approximately 1.4. The four discrete probabilities to be used are also indicated in Fig. 7 and Table 6.

Finally, we still have to motivate the use of different ranges for the triangular distributions in the two-phase procedure: [1,5] with TIAM WORLD in stochastic programming and $[1.1,4.4]$ with GEMINI-E3 in the MC approach. When we perform the MC simulations with GEMINI-E3, the emission path corresponding to a particular Cs value will be obtained by linear interpolation of the paths that have been computed by TIAM WORLD for the four possible branches of the event tree. Hence, the sampled Cs values must be contained in the range of the discretized probability distribution used in TIAM WORLD. Adjusting the triangular distribution to this range of the Cs pdf thus does the trick.

\subsection{Monte Carlo Analysis with GEMINI-E3}

We perform MC simulations of the aggregate GEMINIE3 model, using Latin hypercube sampling [18] from the parameter distributions described in Section 3. MC methods rely on repeated random sampling to generate values for key uncertain input parameters defining scenarios and then identify a probability distribution for some output parameters and/or performance criteria. An experimental design is adopted ensuring that the set of sample values for the uncertain parameters defining the scenarios is randomly generated according to the probability laws governing these processes. If one wishes to ensure that each of the input parameter components has all portions of its distribution represented by input values, one can divide the range of each parameter component into $N$ strata of equal marginal probability $1 / N$ and sample once from each stratum.
Table 8 Summarized stochastic parameters

\begin{tabular}{ll}
\hline Uncertainty & Probability distribution \\
\hline Elasticity between aggregate inputs & $\sigma \sim N(\bar{x}, 0.3 \cdot \bar{x})$ \\
Elasticity between energy inputs & $\sigma_{\mathrm{e}}, \sigma_{\mathrm{ef}} \sim N(\bar{x}, 0.3 \cdot \bar{x})$ \\
Autonomous energy efficiency improvement & aeei $\sim N(\bar{x}, 0.4 \cdot \bar{x})$ \\
Economic growth of ASI & gasi $\sim N(\bar{x}, 0.15 \cdot \bar{x})$ \\
Economic growth of ROW & grow $\sim N(\bar{x}, 0.15 \cdot \bar{x})$ \\
Oil price & poil $\sim N(\bar{x}, 0.25 \cdot \bar{x})$ \\
Year of commercial availability of CCS & yccs $\sim \operatorname{Bernoulli}(0.5)$ \\
Cost of CCS & $\operatorname{ccs} \sim U(0,1)$ \\
Climate sensitivity & Cs $\sim \operatorname{Triangular}(1.1,2.9,4.4)$ \\
\hline
\end{tabular}


Fig. 8 Energy consumption in Mtoe in the BAU deterministic scenario

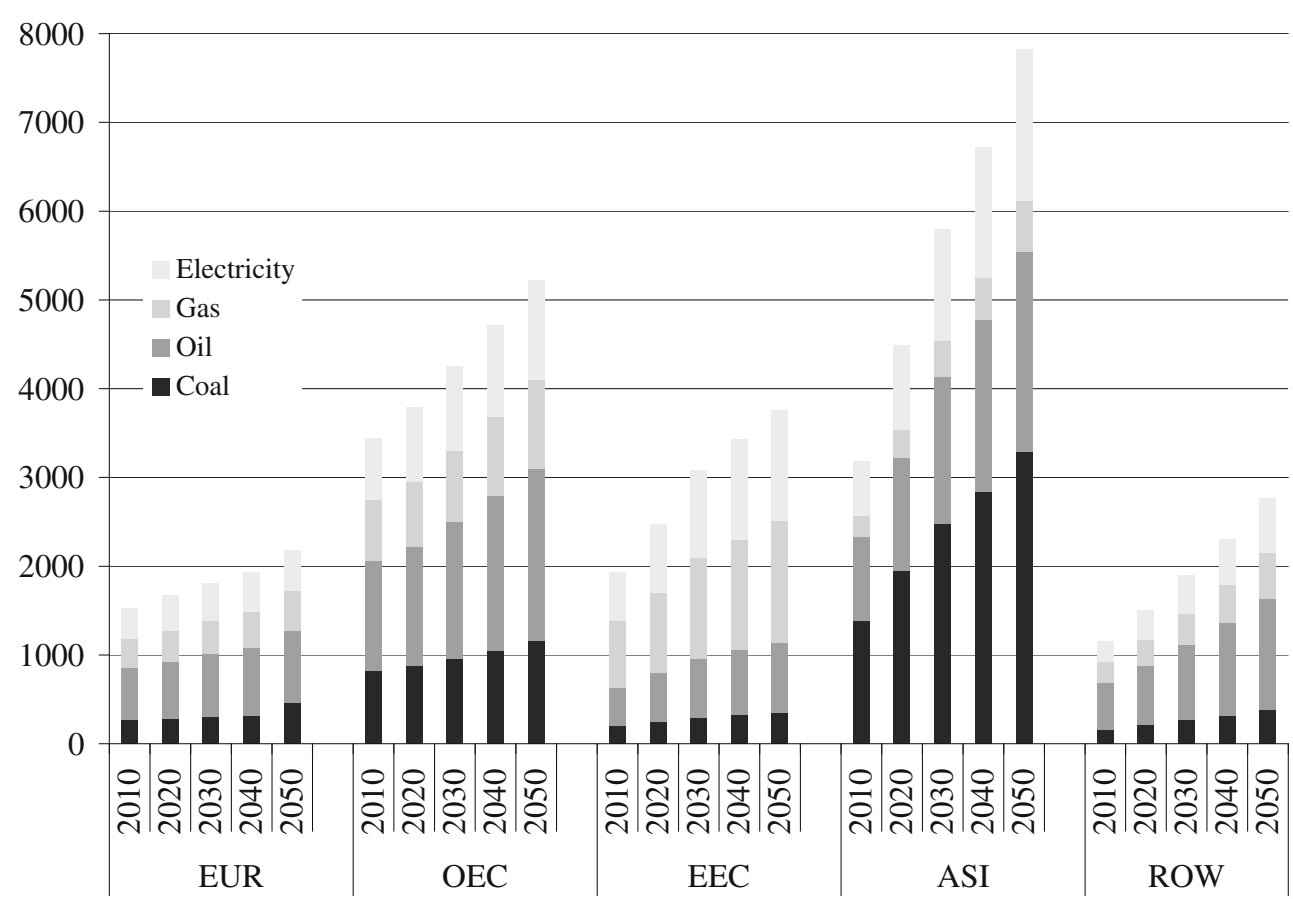

These samples for each component are then matched at random. This is called the Latin hypercube sampling [18]. This is one of several possible "space-filling" experimental designs. The output parameters are then computed optimally for each scenario. In the final step, these results are analysed through an identification of their probability distributions. In the $E^{3}$ case, one obtains indicators of the likelihood of different long- term output parameters related to climate, economy and energy prices.

The advantages of this method are twofold. First, its simplicity; it does not require any specific modifications of the model. The user only needs to sample judiciously the set of scenarios, and then simulations can be run straightforwardly. Second, the model size does not increase with the sample size and so a large enough
Fig. 9 Electricity generation in Twh in the BAU deterministic scenario

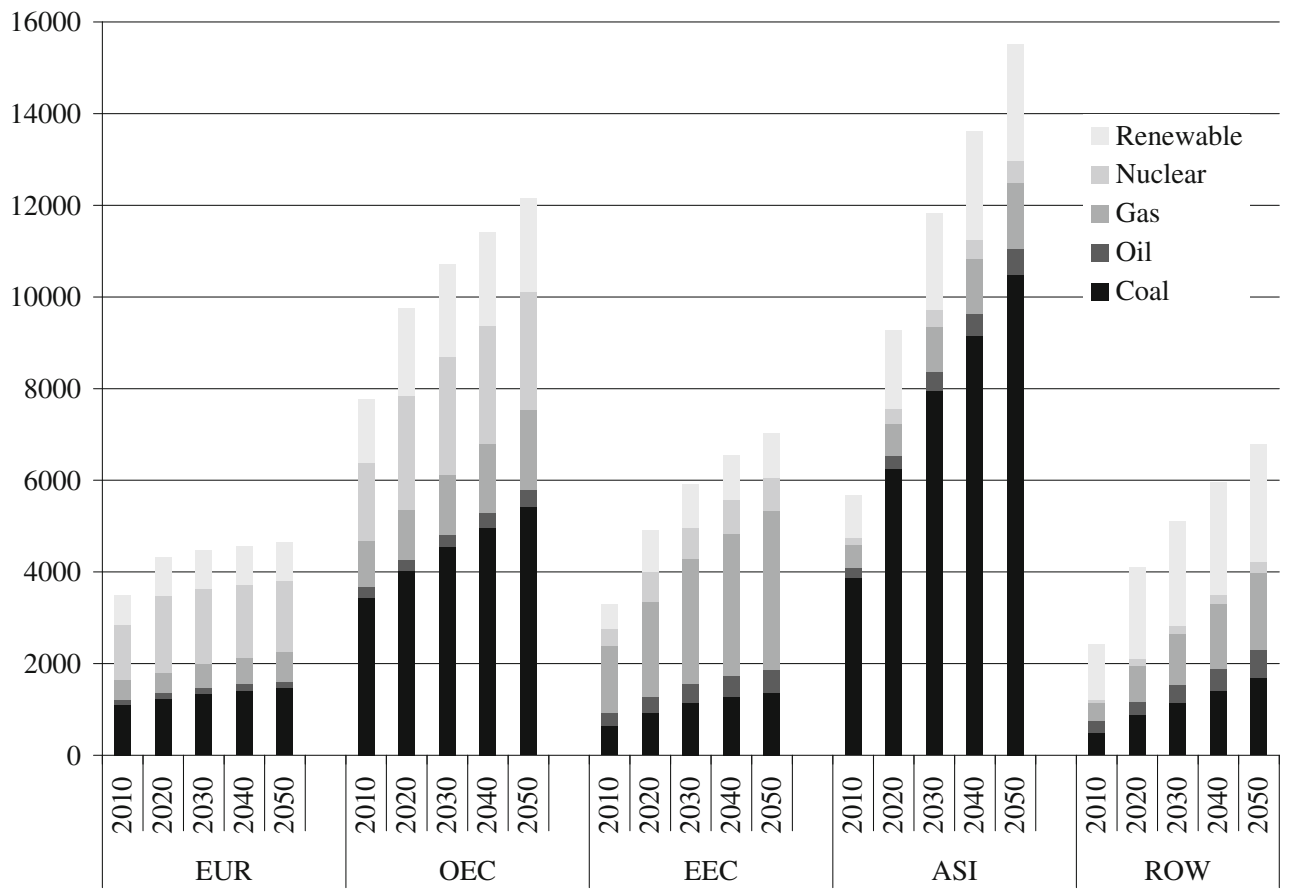


Fig. 10 GHG emissions in

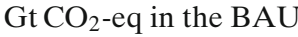
deterministic scenario

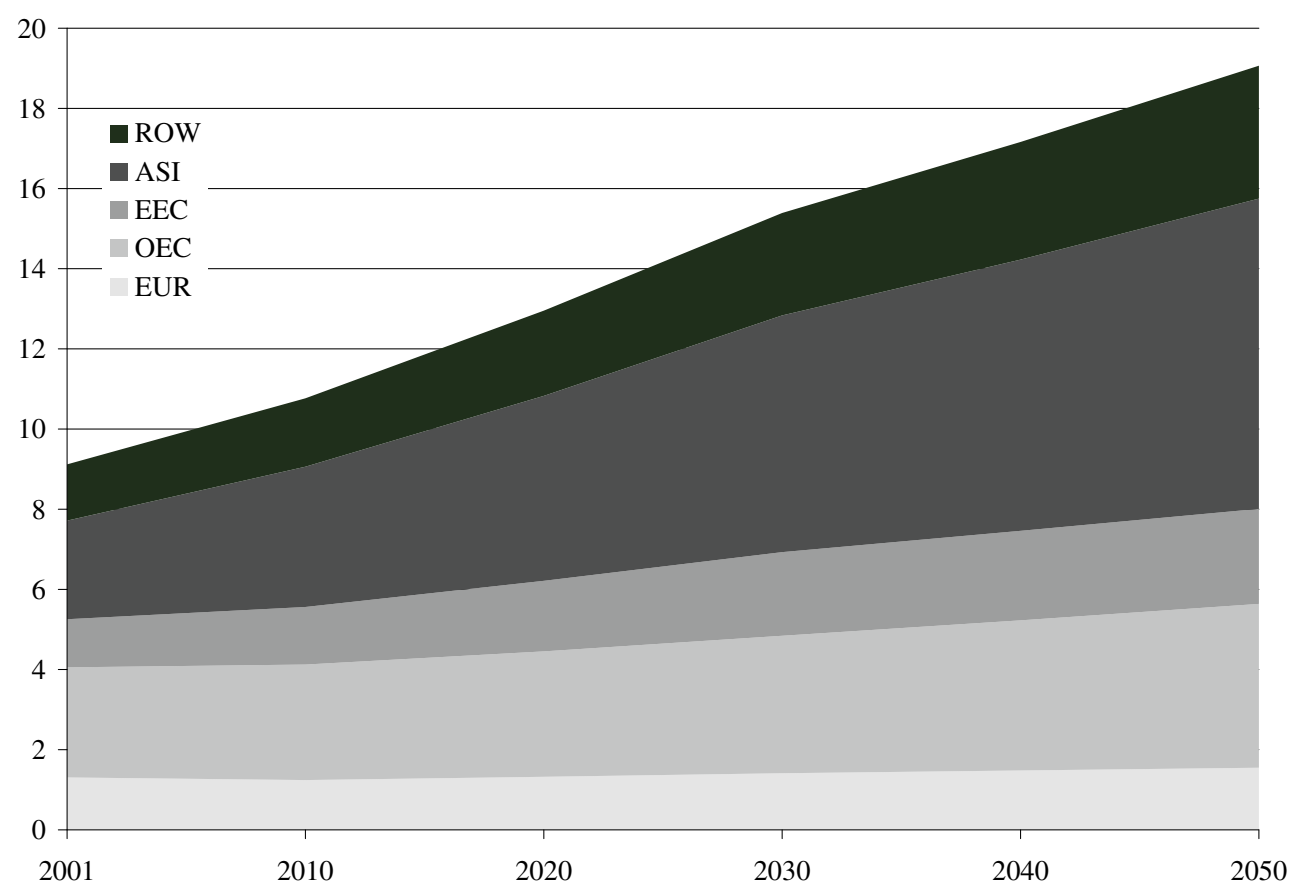

sample set and scenario computations can be obtained to identify the probability distributions of the output parameters of interest.

The simulations presented here are based on 2,000member ensembles, and each sample is simulated under a reference case scenario and under a climate policy scenario. The latter one has an objective in 2100 in global temperature increase of $2.1^{\circ} \mathrm{C}$ above preindustrial levels. We suppose that the climate change target is implemented through a worldwide $\mathrm{CO}_{2}$ emission market which begins in 2011, and the quotas of each region are defined in respect to the rules proposed in the second best scenario 2 (SC2) of the FP7
European Research Project PLANETS (see [26]). In this SC2 scenario, it is assumed that the set of emissions quotas (commitments) is defined, by specifying the starting date of the commitment (before that date, emissions are assumed to be those in the reference case) and the percentage emission reduction in 2050 with respect to emissions in 2005. It is also assumed that the reductions occur linearly from start date to 2050. Concerning European Union, we supposed that its objective of $20 \%$ emission reduction w.r.t. 1990 by 2020 [11] is also implemented from 2008. On the basis of these rules, we compute on the period 2005 to 2050 the share of each region in the cumulative $\mathrm{CO}_{2}$
Table $9 \mathrm{CO}_{2}$ price, $\mathrm{GHG}$ abatement and tradable permits in the deterministic scenario

\begin{tabular}{lllll}
\hline & 2020 & 2030 & 2040 & 2050 \\
\hline CO $_{2}$ price in US\$ & 11 & 17 & 44 & 87 \\
GHG abatement in \% wrt BAU & & & \\
EUR & -7.7 & -11.3 & -22.0 & -30.0 \\
OEC & -9.8 & -15.0 & -29.1 & -40.4 \\
ASI & -18.2 & -29.9 & -42.8 & -52.2 \\
EEC & -12.6 & -21.9 & -33.9 & -45.1 \\
ROW & -12.0 & -19.7 & -29.7 & -39.0 \\
World & -13.3 & -22.1 & -34.6 & -44.7 \\
Exchange of permits in MtC-eq $(-):$ buying & & & \\
EUR & -437 & -414 & -371 & -347 \\
OEC & $-1,026$ & -996 & -859 & -748 \\
ASI & +717 & +657 & +619 & +515 \\
EEC & +259 & +289 & +318 & +387 \\
ROW & +488 & +465 & +293 & +193 \\
Sum & 0 & 0 & 0 & 0 \\
\hline
\end{tabular}


Fig. 11 Change in energy consumption in 2050 in percent wrt BAU in the deterministic scenario

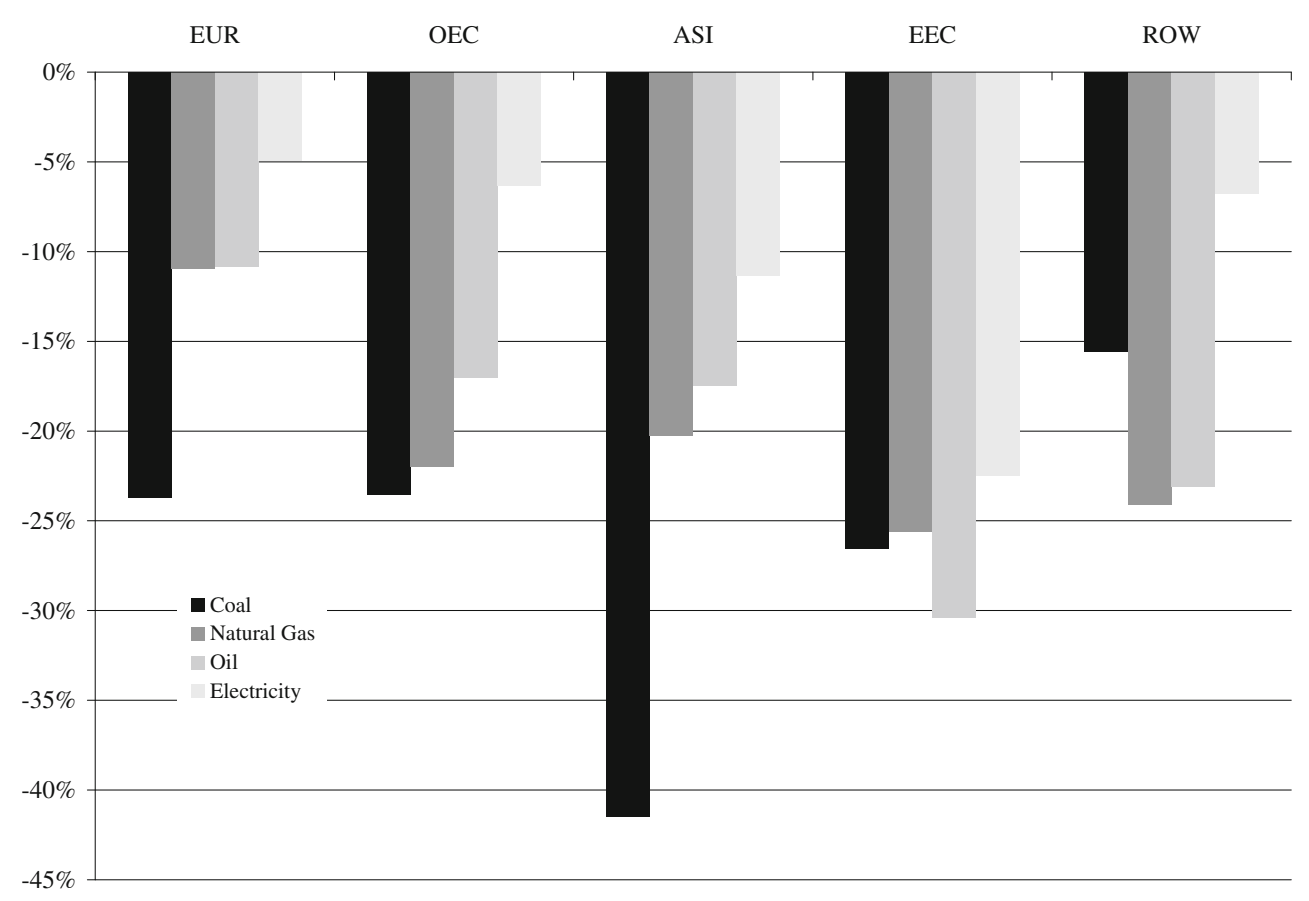

allocation which gives the weight applied to compute for each year the allocation of quota by region in the climate policy scenario. Table 7 summarizes these assumptions and gives the computed weight.

\subsection{Summary on Uncertain Parameters}

We summarize in Table 8 the uncertain parameters under study and the probability distributions used in the Latin hypercube procedure.

\section{Numerical Results}

In the numerical study, we draw 2,000 samples with Latin hypercube technique from the parameter distributions described in Table 8. For each sample, we proceed in two steps:

- In step one, we run a BAU scenario, without any climate policy.

- In step two, we perform a climate policy scenario as it was described in Section 4.2.

At the end, we have performed 4,000 runs. We give below our analyses on both types of runs, respectively.

We have also performed a deterministic run that will be used in the stochastic analysis to compare the output of this "average deterministic" run and the average of the output in the MC analysis.

\subsection{Average Deterministic Results}

In this section, we report the main results from the average deterministic run for both BAU and climate policy scenario. We give to all stochastic parameters their mean values, and we assume the optimistic date of availability of CCS in 2020.

\subsubsection{BAU Scenario Analysis}

Figure 8 shows the resulting energy consumption in the five parts of the world that we distinguish. The world energy consumption would increase by $1.6 \%$ per year, and the key driver of energy consumption is the GDP growth: The growth of energy consumption would be sustained in Asia and in the rest of the world (respectively $+2.3 \%$ and $2.2 \%$ per year) and moderate in the OECD countries $(0.7 \%$ in EUR and $1 \%$ in OEC). In

Table 10 Welfare cost (surplus in percent of household consumption) in the deterministic scenario

\begin{tabular}{llllr}
\hline & $\begin{array}{l}2020 \\
(\%)\end{array}$ & $\begin{array}{l}2030 \\
(\%)\end{array}$ & $\begin{array}{l}2040 \\
(\%)\end{array}$ & \multicolumn{1}{c}{$\begin{array}{l}2050 \\
(\%)\end{array}$} \\
\hline EUR & -0.07 & -0.01 & -0.13 & -0.55 \\
OEC & -0.29 & -0.31 & -0.65 & -1.20 \\
ASI & 1.73 & 2.05 & 3.42 & 3.69 \\
EEC & -2.76 & -4.30 & -10.22 & -16.45 \\
ROW & -0.16 & -0.38 & -1.98 & -4.21 \\
World & -0.03 & -0.01 & -0.37 & -1.16 \\
\hline
\end{tabular}


Table 11 Logit model on the BAU scenario convergence (0 if convergence; 1 otherwise)

In bold: most significant values

\begin{tabular}{lcccc}
\hline & Estimate & Standard error & $z$ value & $\operatorname{Pr}(>|z|)$ \\
\hline Intercept & 11.86 & 1.37 & 8.669 & $<2 \mathrm{e}-16$ \\
aeei & 0.00 & 0.26 & -0.004 & 0.996 \\
$\sigma$ & -15.69 & 0.93 & $-\mathbf{1 6 . 9 1 1}$ & $<2 \mathrm{e}-16$ \\
$\sigma_{\mathrm{e}}, \sigma_{\text {ef }}$ & -0.06 & 0.33 & -0.185 & 0.854 \\
gasi & -0.88 & 0.67 & -1.315 & 0.189 \\
grow & 0.38 & 0.68 & 0.568 & 0.57 \\
poil & -0.36 & 0.41 & -0.867 & 0.386 \\
\hline
\end{tabular}

2050, DCs (EEC, ASI and ROW) represent $66 \%$ of energy consumption against $56 \%$ in 2010 . The energy mix of the economy is mainly driven by the change of the relative energy prices and by technological change. As in this scenario, we do not assume different trends in fossil energy prices and technological breakthrough, and the energy mix remains almost unchanged over the period. In 2050, oil would continue to remain the dominant energy: Oil represents $32 \%$ of world energy consumption, and the transport sector would remain the main user of oil without significant penetration of biofuels and other potential substitutes. Electricity and coal contribute to $25 \%$ each of the energy balance, and gas equals only $18 \%$ of energy consumption.

Figure 9 gives the electricity generation by fuel, and world electricity generation rises from $22,600 \mathrm{TWh}$ in 2010 to 38,000 TWh by 2030 and to 46,000 TWh by 2050. Without any constraint on the deployment of power plants (such as a nuclear phase out) and taking into account the fact that the hierarchy among energy prices remains unchanged, the new installed capacities do not modified the structure of electricity generation

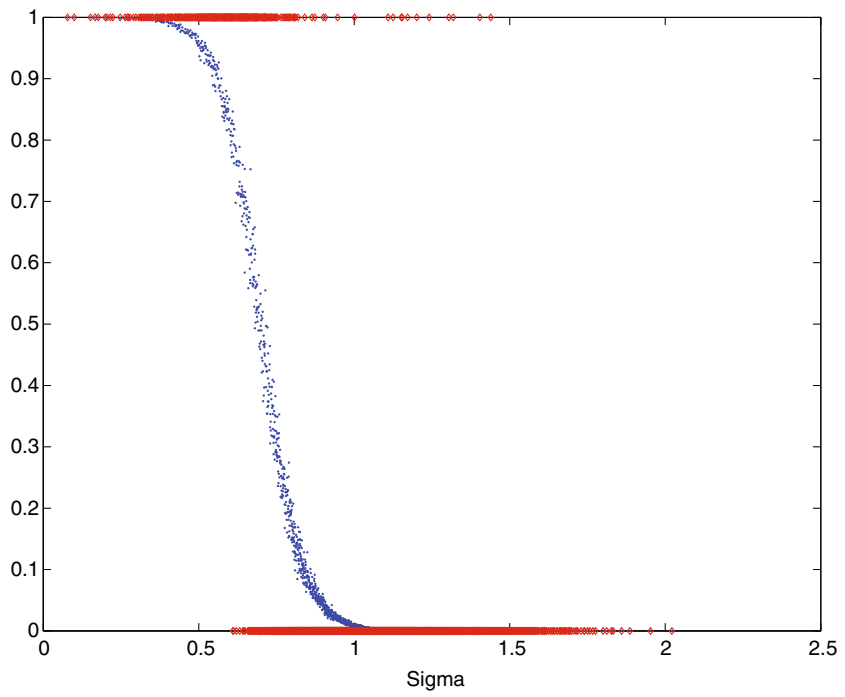

Fig. 12 Probability of convergence in function of $\sigma$ within each region. Coal remains the dominant energy in electricity generation in Asia, and in less extent in OEC, electricity generation from nuclear is mainly located in developed countries, and energy exporting countries continue to use mainly oil and natural gas to produce electricity. Without any climate change policy or environmental constraint (such as local air pollution control or EU target on the penetration of renewable energy by 2020), there is no strong penetration of renewable in the energy mix. Finally, in Fig. 10, we show the resulting evolution of GHG emissions levels from the five groups of countries under consideration.

\subsubsection{Climate Policy Scenario Analysis}

In the average deterministic case, the emission trajectory is obtained from the deterministic run of TIAM WORLD with $2.9^{\circ} \mathrm{C}$ value for Cs (see Table 3). Table 9 shows the price of $\mathrm{CO}_{2}$; in 2030, the permit price would be equal to US $\$ 11$ and in 2050 to US $\$ 87$. Mitigation opportunities are comparable between regions, even if they are significantly higher in Asia and energy exporting countries. The exchange of tradable permits results from the abatement opportunities and the initial

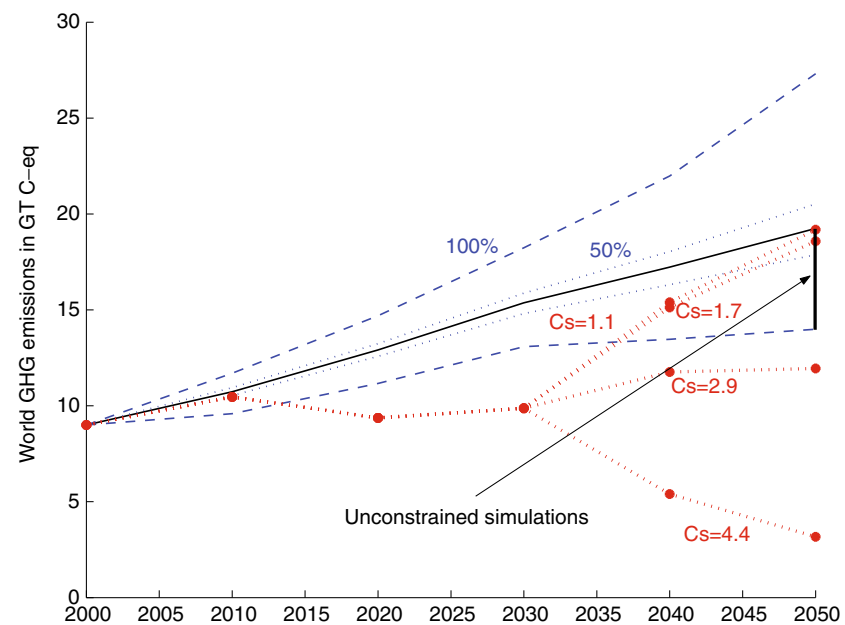

Fig. 13 Uncertainty in emissions projections 
endowments of permits, as it can be seen in Table 9 that industrialized countries would be net buyers and other countries net seller. Figure 11 shows the change in energy consumption by fuel in percent with respect to baseline in 2050. The changes in consumption depend on the energy mix in the baseline, the possibilities of substitution, the $\mathrm{CO}_{2}$ content of each energy and the existing energy taxation. Electricity consumption is less affected, and the possibilities to produce electricity from non- $\mathrm{CO}_{2}$ energy sources (nuclear, renewable) and to use CCS with coal power generation limit the impact of the $\mathrm{CO}_{2}$ price on the price of electricity. At the world level, $74 \%$ of electricity generation done with coal power plan uses CCS in 2050. The use of CCS limits the drop in coal consumption which remains important, and this decrease is mainly due to the declining use of coal in the economy (excluding electricity generation) and to the decrease of electricity consumption, which impacts the production of coal power plant. The decrease of oil and natural gas consumption is also important and comparable in magnitude.

Table 10 presents the welfare cost; at the world level, this cost reaches $1.2 \%$ of the households consumption in 2050. The welfare cost by regions are quite different, and they depend mainly on three factors:

- The cost of mitigation (i.e. deadweight loss of taxation)

- The initial endowment of GHG permits

- The gains or loss coming from terms of trade

Asia benefits from the selling of permits and gains coming from terms of trade, and its surplus is positive and equals to $3.7 \%$ of the household consumption in 2050. On the contrary, despite sales of permits, energy exporting countries is severely penalized by a drop in its revenue coming energy exports, and its welfare cost reaches $16 \%$ of its household consumption in 2050 . The ROW is in a situation comparable to that of energy exporting countries because this region includes substantial energy exporting countries such as Venezuela, Nigeria, Algeria and Libya, and the cost is evaluated at $4.2 \%$ of the household consumption. Finally, the cost for industrialized countries is rather limited, with these countries benefitting from gains related to terms of trade and to low abatement since GHG emissions do not increase much over the period of simulation. This is particularly the case in European countries where weak GDP growth combined with low-energy intensity leads to a GHG emissions increase at the end of the simulation in the baseline scenario which is half of that concerning the OEC region. The cost for EUR is equal to $0.5 \%$ of the household consumption, to be compared with the cost for OEC $(1.2 \%$ of the household consumption).

\subsection{Analysing Uncertainty on BAU Scenarios}

We report, in the section, the main results from the BAU scenarios. We also have noticed that the output of the deterministic BAU scenario corresponds approximately to the average of the stochastic output. This results was expected as no climate policy constraint is imposed on the BAU scenarios.

\subsubsection{Economic Flexibility and Convergence}

In $17 \%$ of BAU scenarios, GEMINI-E3 does not converge, and these runs are infeasible. To interpret this result, we use a logit model where the dependent variable is equal to one if the run is infeasible and 0 otherwise and where the explanatory variables are the uncertain parameters. In Table 11, one observes that only one
Table 12 Estimate of the $\log ($ emission $)$ in 2050

\begin{tabular}{lcccccc}
\hline & World & EUR & OEC & ASI & EEC & ROW \\
\hline Intercept & 9.848 & 7.336 & 8.305 & 8.946 & 7.753 & 8.101 \\
& $(11710.3)$ & $(9025.7)$ & $(11771.3)$ & $(8445.5)$ & $(8266.3)$ & $(15911.1)$ \\
$\log ($ aeei $)$ & -0.168 & -0.178 & -0.143 & -0.201 & -0.192 & -0.096 \\
& $(-102.8)$ & $(-112.7)$ & $(-104.7)$ & $(-98.1)$ & $(-105.6)$ & $(-97.2)$ \\
$\log (\sigma)$ & -0.012 & 0.033 & -0.012 & -0.012 & 0.036 & -0.064 \\
& $(-3.3)$ & $(9.4)$ & $(-3.9)$ & $(-2.6)$ & $(8.9)$ & $(-29.3)$ \\
$\log \left(\sigma_{\mathrm{e}}\right)$ & 0.003 & 0.001 & -0.003 & 0.017 & -0.014 & -0.008 \\
& $(1.3)$ & $(0.3)$ & $(-1.7)$ & $(6.0)$ & $(-5.8)$ & $(-6.3)$ \\
$\log ($ poil $)$ & -0.131 & -0.203 & -0.210 & -0.072 & -0.132 & -0.131 \\
& $(-40.3)$ & $(-64.9)$ & $(-77.3)$ & $(-17.8)$ & $(-36.6)$ & $(-66.7)$ \\
$\log ($ gasi $)$ & 0.295 & 0.029 & 0.006 & 0.688 & 0.076 & 0.026 \\
& $(58.3)$ & $(-64.9)$ & $(1.5)$ & $(107.8)$ & $(13.5)$ & $(8.5)$ \\
$\log ($ grow $)$ & 0.065 & 0.010 & 0.007 & 0.011 & 0.010 & 0.332 \\
& $(13.0)$ & $(5.9)$ & $(1.7)$ & $(1.8)$ & $(1.8)$ & $(109.6)$ \\
Adjusted $R^{2}$ & 0.90 & 0.91 & 0.91 & 0.93 & 0.89 & 0.94 \\
\hline
\end{tabular}




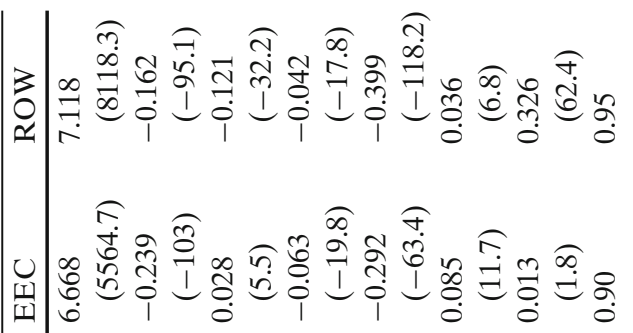

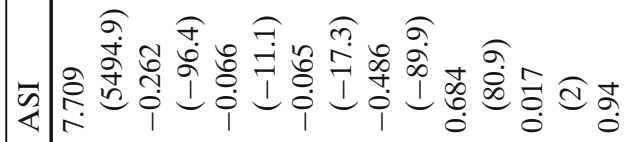

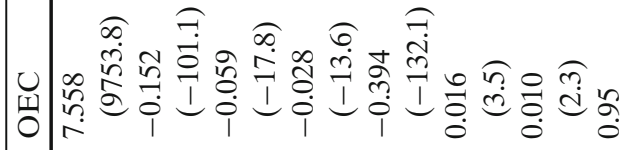

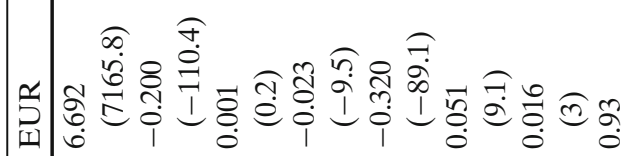

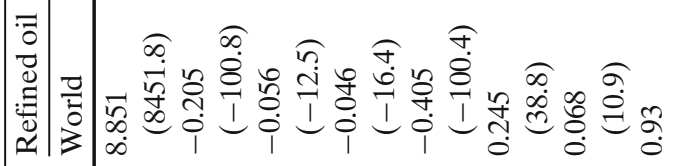

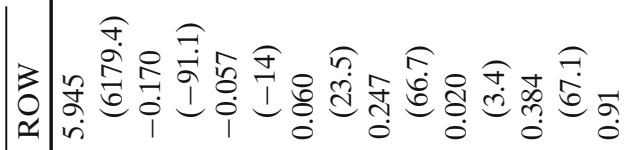

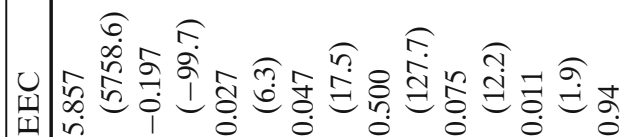

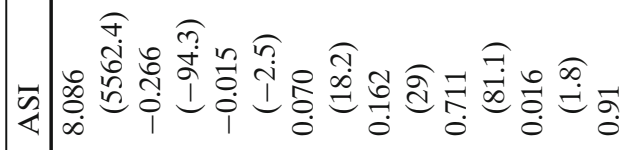

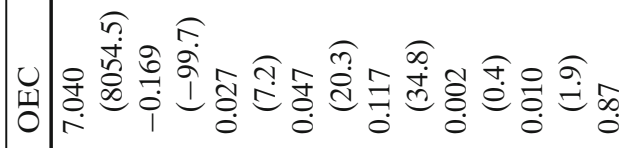

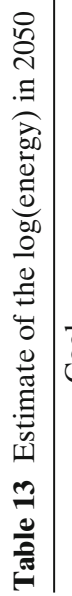

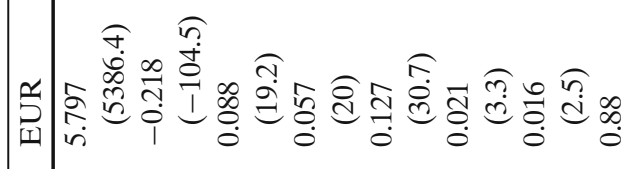

Эิ

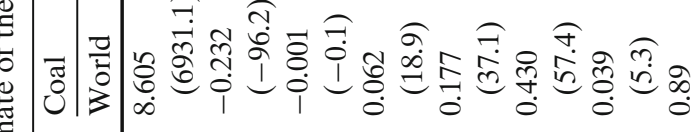


parameter is significant, namely $\sigma$ which is related ${ }^{9}$ to the elasticity of substitution between aggregate inputs (labour, capital, energy and other materials); this is a measure of flexibility of the economy. When the value of the $\sigma$ parameter is small, the economic flexibility is too weak, and GEMINI-E3 could not find any solution and does not converge.

Figure 12 gives the probability of non-convergence of a scenario as a function of the $\sigma$ values. All $\sigma$ values simulated in the experiments are plotted (in small diamonds) either at the top or at the bottom of the figure depending on non-convergence or convergence of the scenario, respectively. One observes that the critical value of the elasticity multiplier $\sigma$ for convergence with probability $\frac{1}{2}$ is around 0.7 . This means that when the value of the elasticities is reduced by $30 \%$, the probability of convergence is equal to $\frac{1}{2}$.

\subsubsection{Impact of Energy Consumption Uncertainty on GHG Emissions}

If we consider the runs that have converged $(1,660$ runs out of a sample of size 2,000), it is interesting to take a look at the uncertainty regarding greenhouse gas emissions. Figure 13 presents the GHG emissions of the BAU scenarios and gives the $50 \%$ (dotted lines) and $100 \%$ (bold dotted lines) probability bounds of these emissions. In 2050, the median value of GHG emissions is located at $19.1 \mathrm{Gt}$ of C-eq, the higher value is equal to 27.3 and the lowest value is less than 13.6. Our scenarios overlap the range of emissions covered by the SRES scenarios published by the IPCC [19], except the scenario A1FI in which the GHG emissions reach more than $30 \mathrm{Gt}$ of C-eq in 2050. We draw on Fig. 13 (dotted line with asterisk marker) the emission trajectories coming from the TIAM WORLD stochastic climate constraint runs, and we observe that when the climate sensitivity is low, there are some runs which would not be constrained in 2050. On contrary, it should be noted that all runs are constrained in 2030.

We estimate a log-linear model concerning the GHG emissions and energy consumption by fuels in 2050 with uncertain parameters as explanatory variables, and Tables 12 and 13 present these estimations at the world level and by regions. The results of these estimations are always statistically significant, as can be easily seen from the adjusted $R^{2}$ which are never below 0.87 . GHG emissions are of course negatively related to technical

\footnotetext{
${ }^{9}$ Because the elasticities are different among sectors, we use here the parameter $\sigma$ which is used as a multiplier to the nominal elasticities (i.e. when GEMINI-E3 is used without uncertainties).
}

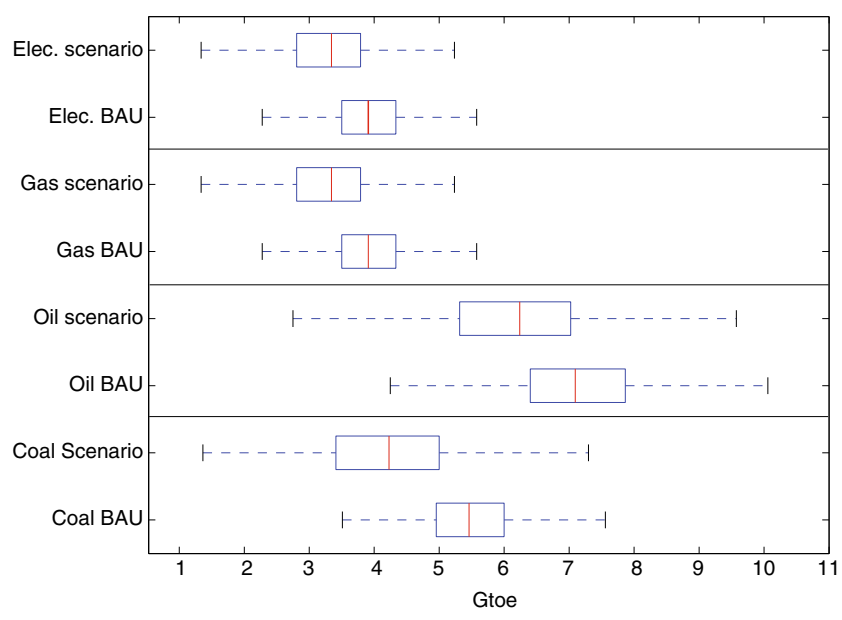

Fig. 14 Energy consumption in 2050

progress on energy (aeei). At the world level, the impact of economic growth in Asia is crucial to global emissions (0.295), and the economic growth of ROW is of secondary importance (0.065). This is due to the weight of Asia in global energy consumption, and its energy mix based largely on coal. We find also that the economic growths of ASI and ROW increase the emissions of the other regions due to the trade effect, and again the impact of Asia is more important than the ROW. An increase in oil prices reduces emissions of greenhouse gas emissions $(-0.131)$ and despite its positive impact on coal consumption, but this negative impact is much more important in industrialized countries and quite less important in Asia; again the explanation comes from the energy mix of each region. The effects of elasticities $\left(\sigma\right.$ and $\left.\sigma_{\mathrm{e}}-\sigma_{\mathrm{ef}}\right)$ are weaker and more ambiguous and must be connected to energy mix and industrial structure of each region. The effect of the elasticity directly related to substitution within energy

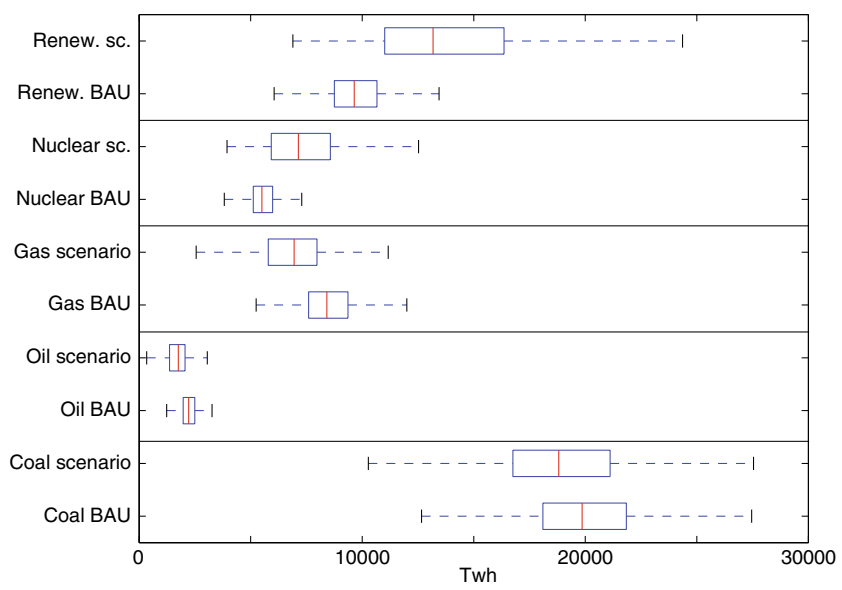

Fig. 15 Electricity generation in 2050 
Table 14 Logit model on the climate policy scenario convergence ( 0 if convergence; 1 otherwise)
In bold: most significant values

\begin{tabular}{lcccc}
\hline & Estimate & Standard error & $z$ value & $\operatorname{Pr}(>|z|)$ \\
\hline Intercept & 9.64 & 27.29 & 0.353 & 0.72383 \\
yccs & 0.00 & 0.01 & -0.046 & 0.96307 \\
ccs & -0.07 & 0.23 & -0.293 & 0.76941 \\
aeei & 0.20 & $\mathbf{- 7 . 6 0 1}$ & $2.95 \mathrm{e}-14$ \\
$\sigma$ & -1.51 & 0.75 & $\mathbf{- 1 3 . 1 7}$ & $<2 \mathrm{e}-16$ \\
$\sigma_{\mathrm{e}}, \sigma_{\text {ef }}$ & -9.88 & 0.23 & $\mathbf{- 3 . 1 0 5}$ & 0.0019 \\
gasi & -0.73 & 0.47 & 1.456 & 0.14542 \\
grow & 0.68 & 0.45 & -1.839 & $6.60 \mathrm{e}-02$ \\
poil & -0.83 & 0.39 & $\mathbf{9 . 3 4 7}$ & $<2 \mathrm{e}-16$ \\
obj2050 & 3.64 & 0.01 & $\mathbf{- 9 . 2 5 4}$ & $<2 \mathrm{e}-16$ \\
\hline
\end{tabular}

$\left(\sigma_{\mathrm{e}}-\sigma_{\mathrm{ef}}\right)$ is more clear on energy consumption. Coal and electricity consumption are positively related to the parameters $\sigma_{\mathrm{e}}$ and $\sigma_{\mathrm{ef}}$; in contrary, oil and natural gas are negatively related. When these elasticities increase, it is more easy to replace oil and natural gas when the oil price increase ${ }^{10}$ by electricity and coal, and all other things held constant.

Figures 14 and 15 present the uncertainties on energy consumption and electricity generation by fuels in the form of Tukey box plots in which the box indicates the $50 \%$ probability range, the line within the box gives the median value and the whiskers indicate the $95 \%$ range. When a climate constraint is taken into account, this induces a decrease of energy consumption in average, but the uncertainty range is more important. In the case of electricity generation, the climate policy scenarios result in a large increase of generation from renewable with a quite important range of uncertainty. The nuclear generation increases also but in a smaller proportion. The case of generation from coal is interesting, and the figures between climate policy scenarios and the BAU scenarios are comparable showing that the use of CCS allows to continue to burn coal for electricity generation.

\subsection{Analysing Uncertainty in Climate Policy Scenarios}

On the basis of the 1,660 BAU scenarios which have converged, we run the climate policy scenarios. Among these 1,660 runs, 9\% become infeasible under a climate policy. Therefore, we estimate a new logit model where the dependent variable is equal to one if the run is infeasible and 0 otherwise with uncertain parameters as explanatory variables. Table 14 gives the estimation. Compared to the estimation done for the BAU scenarios, we add three variables: the cost of CCS (ccs), the year of CCS availability (2020 or 2030, yccs) and the

\footnotetext{
${ }^{10}$ Note that we suppose that the natural gas price is indexed on oil price, see Section 3.4.
}

GHG target in 2050 (obj2050). Three factors explain this infeasibility:

- The first factor is related to the "state of technology" which is represented in a CGE by the value of the elasticities $\left(\sigma, \sigma_{\mathrm{e}}, \sigma_{\mathrm{ef}}\right)$. The probability of achieving the climate target is increasing with the value of these elasticities. The parameter aeei may also be included in this category because it represents the technical progress associated to energy consumption.

- The second factor is of course linked to the climate target itself (obj2050); if the climate sensitivity is too high (which means that obj2050 is too low), then the model could not reach this target. This impossibility to meet stringent (ambitious) climate target has been highlighted recently in the study done by the Energy Modeling Forum [10]. This study shows that the 450-ppmv $\mathrm{CO}_{2}$-eq concentration target is infeasible for 12 of 14 models used if concentrations are not allowed to temporarily exceed their long-term targets. If overshooting is allowed, eight of 14 models were able to produce a 450-ppmv $\mathrm{CO}_{2}$-eq case. Remember that with a climate sensitivity equal to 3 , the 450-ppmv $\mathrm{CO}_{2}$ eq concentration target will result in a temperature change relative to preindustrial around $1.9-2.2^{\circ} \mathrm{C}$.

- Finally, the oil price also affects the possibility of reaching a target climate, when it increases the probability decreases. This result is counterintuitive because we see that GHG emissions are related negatively to oil price in the BAU scenarios. We interpret this result by the fact that high oil prices led to a more intensive use of coal (see Table 13) and ex-post to an economy in which all decarbonization becomes more difficult.

The uncertainties related to the other parameters do not seem to affect the probability of achieving the climate target, especially the variables related to the CCS (yccs and ccs). The analysis that follows below focuses now on the runs that have converged both in 

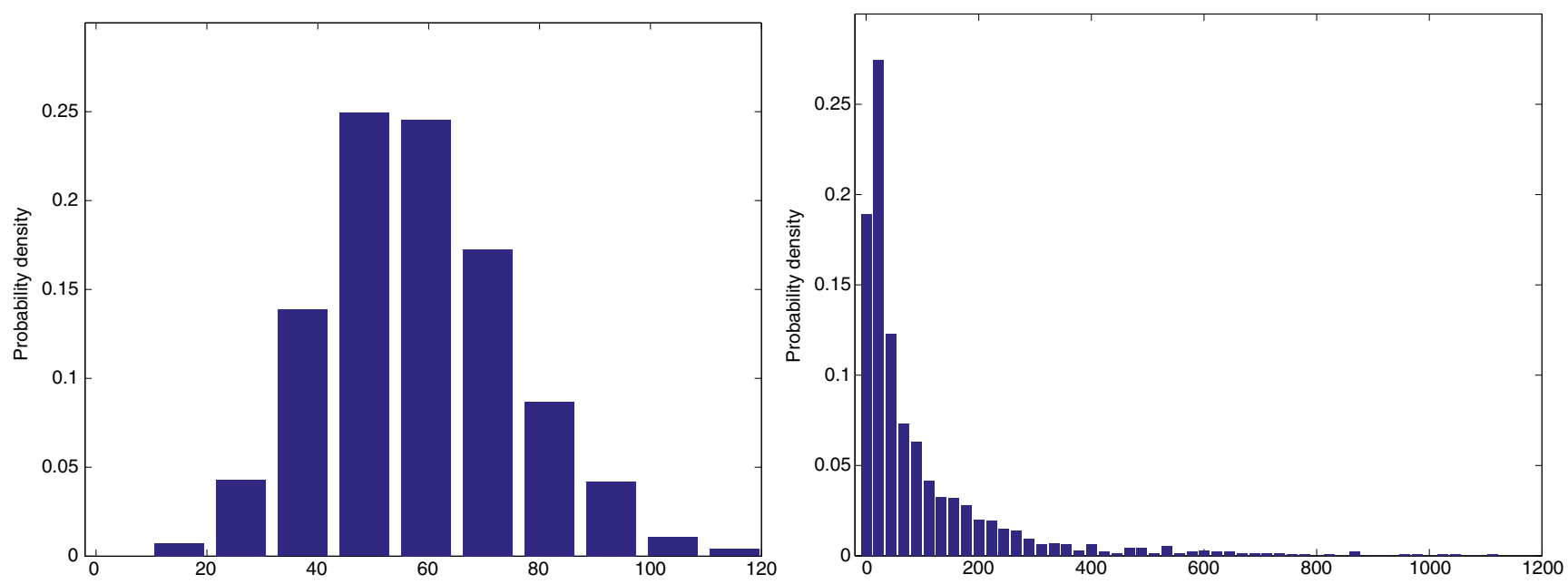

Fig. $16 \mathrm{CO}_{2}$ price in US\$ in 2030 (left) and 2050 (right)

the BAU scenarios and in the climate policy scenarios, that is to say 1,508 runs.

\subsubsection{Impact of Uncertainty on $\mathrm{CO}_{2}$ Price}

Figure 16 shows the probability distributions of carbon prices in 2030 and 2050. We estimate these carbon prices on the uncertain parameters, and these estimates are presented in Table 15. The results of these estimations are statistically satisfactory, and all the explanatory variables are significant and have the expected sign.

In 2030, there is no uncertainty in the GHG emissions target due to the used hedging strategy (we find a single hedging emission profile until 2030, see Section 3.1), and the variable related to uncertainty on GHG emissions target could not be used. The $\mathrm{CO}_{2}$ price follows a distribution similar to a log normal, the probability range is US $\$ 15$ to $\$ 126$ and the mean of the distribution is US \$63. The most important factors which explain the uncertainty related to $\mathrm{CO}_{2}$ price are in order of decreasing importance the $\sigma$ parameter elasticity of substitution between aggregate inputs), the economic growth of Asian countries, the oil price and the aeei coefficient. Based on these estimates, we compute the relationship between the $\mathrm{CO}_{2}$ price and the $\sigma$ parameter and the rate of growth in Asia. Figure 17 presents these links. The elasticity between $\sigma$ and the $\mathrm{CO}_{2}$ price is equal to 0.7. The relation between the GDP growth of Asian countries and the $\mathrm{CO}_{2}$ price could not be directly computed on the basis of the estimation presented in Table 15 because the coefficient gasi represents the technical progress on labour which is one of the determinants of the growth rate of the GDP. We proceed in two steps: First, we estimate the impact of the technical progress on the GDP, and secondly, we compute the relationship between the GDP growth and the $\mathrm{CO}_{2}$ price based on the estimation of the $\mathrm{CO}_{2}$ price on the uncertain parameters. As it can be seen in Fig. 17 when the annual growth rate of Asia on the period 2010 to 2030 increases by one point, the $\mathrm{CO}_{2}$ increases by US $\$ 16$.

In 2050 , the probability density of the $\mathrm{CO}_{2}$ price appears quite different from that of 2030. Firstly, the shape of the probability distributions is clearly asymmetric which comes from the climate constraint in

Table 15 Estimate of the $\log \left(\mathrm{CO}_{2}\right.$ price $)$

\begin{tabular}{lcc}
\hline & In 2030 & In 2050 \\
\hline Intercept & 4.261 & 23.211 \\
& $(1015.5)$ & $(101.2)$ \\
$\log ($ aeei $)$ & $-\mathbf{0 . 3 1 3}$ & $-\mathbf{0 . 8 4 9}$ \\
& $(-58.8)$ & $(-22.9)$ \\
$\log (\sigma)$ & $-\mathbf{0 . 6 9 2}$ & $-\mathbf{0 . 5 0 7}$ \\
& $(-58.9)$ & $(-6.0)$ \\
$\log \left(\sigma_{\mathrm{e}}, \sigma_{\mathrm{ef}}\right)$ & -0.194 & -0.261 \\
& $(-28.5)$ & $(-5.5)$ \\
$\log ($ poil $)$ & $-\mathbf{0 . 4 0 6}$ & $\mathbf{- 0 . 5 7 7}$ \\
& $(-40.7)$ & $(-8.3)$ \\
$\log ($ gasi $)$ & $\mathbf{0 . 5 6 6}$ & $\mathbf{1 . 1 9 0}$ \\
& $(36.4)$ & $(10.8)$ \\
$\log ($ grow $)$ & 0.140 & 0.432 \\
& $(9.2)$ & $(4.1)$ \\
$\log ($ ccs $)$ & 0.022 & 0.068 \\
& $(9.1)$ & $(4.0)$ \\
yccs & -0.203 & -0.099 \\
& $(-42.3)$ & $(-2.9)$ \\
$\log ($ obj2050) & - & $-\mathbf{5 . 2 6 6}$ \\
& - & $(-86.0)$ \\
Adjusted $R^{2}$ & 0.90 & 0.86 \\
\hline
\end{tabular}

In bold: most significant values 

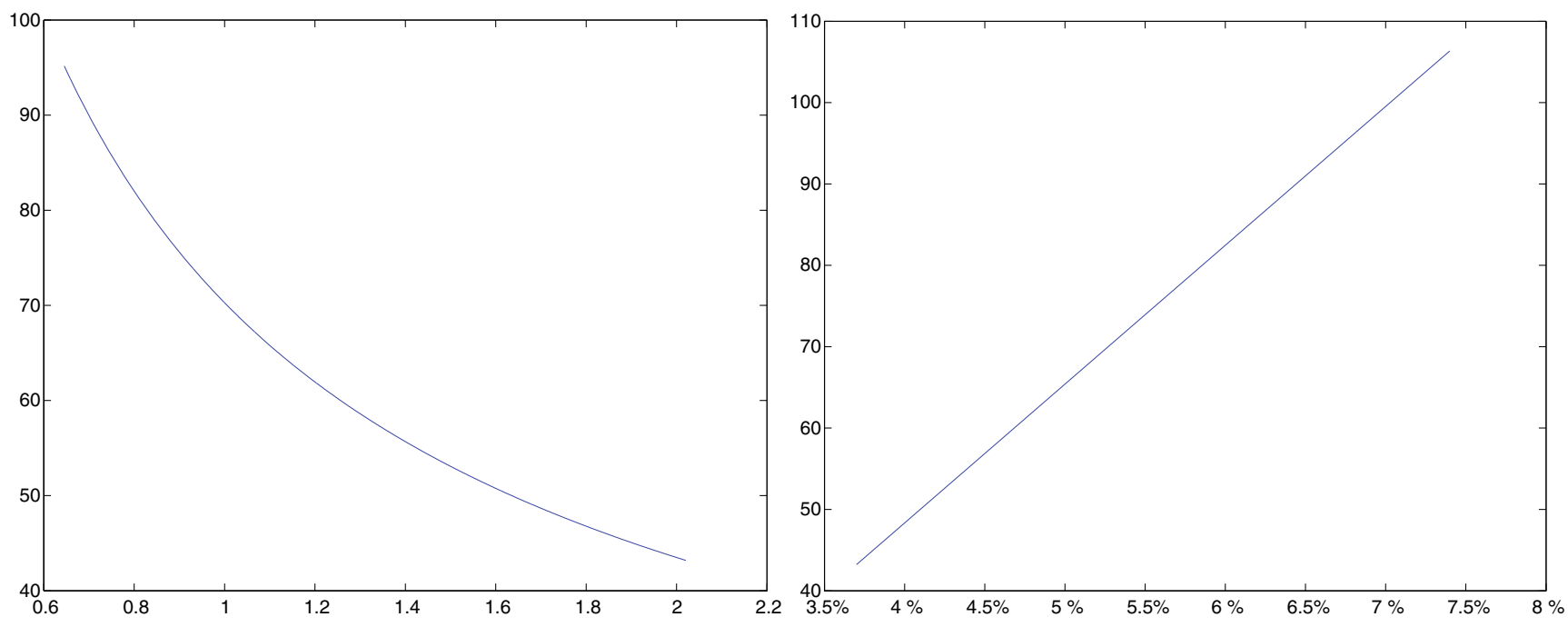

Fig. 17 Relation in 2030 between $\sigma$ and the $\mathrm{CO}_{2}$ price (left) —annual GDP growth of ASI and the $\mathrm{CO}_{2}$ price (right)

which low climate sensitivities lead to weakly binding emission levels. These low emission constraints in 2050 combined with carbon-free investments made before the revelation of uncertainty in climate sensitivity in 2030 led to a zero $\mathrm{CO}_{2}$ price in $19 \%$ of cases. Again in contrary to the year 2030, the probability range of the $\mathrm{CO}_{2}$ price is much more important (US $\$ 0-1,112$ ) even if the mean of the distribution is quite close (US $\$ 84$ ). If we remove observations in which the price is equal to zero and estimate the $\mathrm{CO}_{2}$ price on the uncertain parameters, we obtain the estimate presented in Table 15 for the year 2050. The parameters $\sigma$, gasi, poil and aeei remain significant, but the variable which is the most important is the climate target (obj2050).

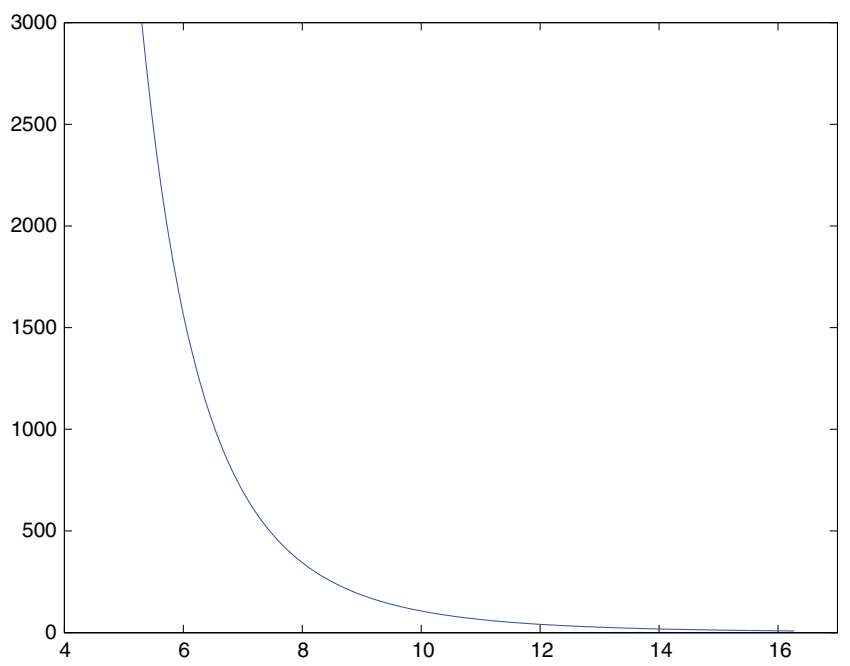

Fig. 18 Relation between GHG emissions target (in GtC-eq) and the $\mathrm{CO}_{2}$ price in 2050
Figure 18 shows the relation between the climate target (obj2050) and the $\mathrm{CO}_{2}$ price; when the GHG emission constraint is below $7 \mathrm{GtC}$-eq, the price increases very rapidly reflecting the difficulty in reaching the climate target.

\subsubsection{Welfare Loss Indicator}

Figure 19 presents the world welfare loss expressed by an indicator which consists of the discounted world surplus (compensative variation of income) divided by the discounted household consumption. Its density distribution is similar to the one of the $\mathrm{CO}_{2}$ price for the year 2050 (see Fig. 16). The world welfare loss ranges from US $\$-14$ trillion to $\$ 89$ trillion with a

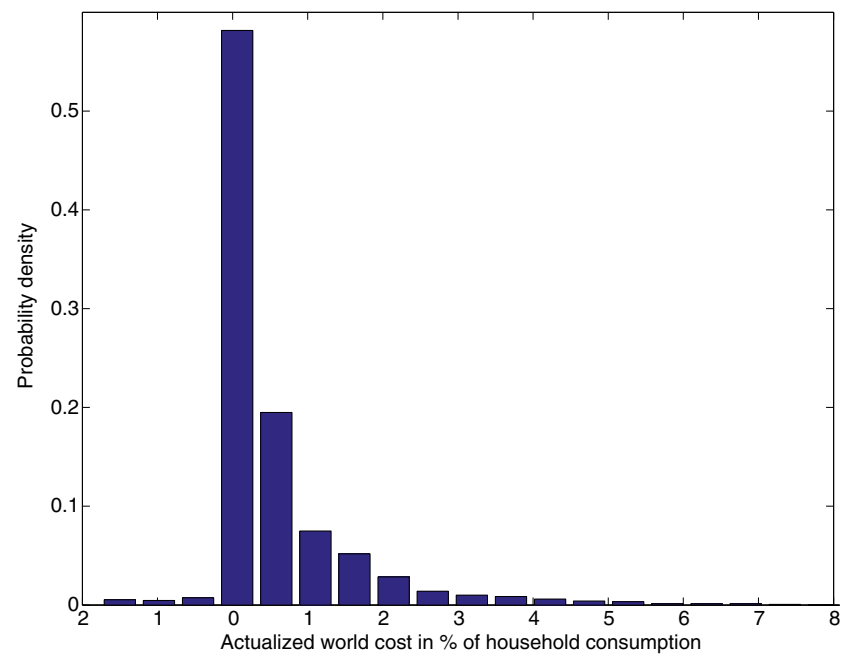

Fig. 19 World welfare loss indicator pdf 
Table 16 Estimate of the welfare cost
In bold: most significant values

\begin{tabular}{lcccccc}
\hline & World & EUR & OEC & ASI & EEC & ROW \\
\hline Intercept & 8.418 & 8.872 & 6.533 & 21.442 & 7.208 & 9.617 \\
& $(107.4)$ & $(37.5)$ & $(90.1)$ & $(12.1)$ & $(87.9)$ & $(109.2)$ \\
$\log ($ aeei $)$ & $-\mathbf{0 . 6 8 1}$ & $-\mathbf{0 . 8 6 3}$ & $-\mathbf{0 . 5 0 9}$ & $-\mathbf{1 . 7 8 5}$ & $-\mathbf{0 . 4 4 0}$ & $-\mathbf{0 . 5 8 5}$ \\
& $(-48.7)$ & $(-20.1)$ & $(-39.4)$ & $(-6.9)$ & $(-30.1)$ & $(-37.3)$ \\
$\log (\sigma)$ & -0.448 & -0.805 & -0.876 & -1.484 & -0.448 & -0.374 \\
& $(-14.2)$ & $(-8.1)$ & $(-30.1)$ & $(-3.1)$ & $(-13.9)$ & $(-10.8)$ \\
$\log \left(\sigma_{\mathrm{e}}, \sigma_{\mathrm{ef}}\right)$ & -0.293 & -0.307 & -0.202 & -1.194 & -0.217 & -0.340 \\
& $(-16.4)$ & $\mathbf{( - 5 . 6 )}$ & $(-12.2)$ & $(-5.1)$ & $(-11.6)$ & $(-16.9)$ \\
$\log ($ poil $)$ & $-\mathbf{1 . 4 0 5}$ & $-\mathbf{3 . 6 2 1}$ & $-\mathbf{1 . 3 9 0}$ & $-\mathbf{1 . 3 4 3}$ & $-\mathbf{0 . 5 8 8}$ & $\mathbf{- 0 . 5 1 1}$ \\
& $(-53.9)$ & $(-41.9)$ & $(-57.7)$ & $(-3.2)$ & $(-21.6)$ & $(-17.5)$ \\
$\log ($ gasi $)$ & $\mathbf{1 . 0 5 1}$ & $\mathbf{0 . 6 3 8}$ & $\mathbf{0 . 6 3 8}$ & $\mathbf{7 . 0 4 9}$ & $\mathbf{0 . 4 5 7}$ & $\mathbf{0 . 3 9 9}$ \\
& $(25.8)$ & $(5.1)$ & $(16.9)$ & $(8.9)$ & $(10.8)$ & $(8.7)$ \\
$\log ($ grow $)$ & 0.209 & 0.077 & 0.060 & -0.332 & 0.062 & 0.880 \\
& $(5.2)$ & $(0.6)$ & $(1.6)$ & $(-0.6)$ & $(1.5)$ & $(19.6)$ \\
$\log ($ ccs $)$ & 0.017 & 0.001 & 0.025 & 0.039 & 0.021 & 0.010 \\
& $(2.7)$ & $(0)$ & $(4.3)$ & $(0.3)$ & $(3.3)$ & $(1.4)$ \\
$\log ($ obj2050) & $-\mathbf{2 . 4 0 7}$ & $-\mathbf{2 . 8 1 7}$ & $-\mathbf{1 . 8 4 7}$ & $-\mathbf{6 . 9 4 3}$ & $-\mathbf{1 . 3 5 4}$ & $-\mathbf{2 . 5 1 9}$ \\
& $(-117.4)$ & $(-45.2)$ & $(-97.4)$ & $(-11.6)$ & $(-63.1)$ & $(-109.4)$ \\
yccs & -0.031 & 0.135 & -0.074 & -0.354 & -0.121 & 0.052 \\
& $(-2.5)$ & $(3.5)$ & $(-6.4)$ & $(-2)$ & $(-9.3)$ & $(3.7)$ \\
Adjusted $R^{2}$ & 0.93 & 0.76 & 0.91 & 0.76 & 0.79 & 0.90 \\
\hline
\end{tabular}

mean of $\$ 8$ trillion. These figures are comparable to those found in [10]. In some very few cases, the world cost is negative (i.e. the climate policy scenario leads to a welfare increase). These are situations in which the climate sensitivity is low and the increase of oil prices high. In these cases, investments made before 2030, leading to lower energy consumption, coincide with a situation of high energy prices, resulting in a way of a perfect foresight in energy prices. Of course, this result must be related to the structure of GEMINI-E3 which assumes adaptive anticipation. Table 16 presents the estimate of the welfare cost on the uncertain parameters. Because we use the logarithm of this welfare cost as an explanatory variable, we remove the negative values of the sample. The results of these estimates are consistent with those of the $\mathrm{CO}_{2}$ price. The most important parameter is the climate target, after come at the world level, the oil price, the growth of Asia and the autonomous energy efficiency improvement. At regional level, we find the same effects with minor differences

\subsubsection{Uncertainty in CCS}

One objective of this paper was to study the role of technology and especially the CCS in climate policies. A cursory reading of our results might suggest that this technology has a limited impact in our scenarios. Indeed, it is true that the parameters linked to CCS (ccs and ycss) have limited impacts and the estimates related to them are not always significant. This does not mean that this technology does not contribute to GHG abatement, but rather that the uncertainty surrounding its costs is of limited scope particularly in respect to the $\mathrm{CO}_{2}$ price. Indeed, in 2030 , in $74 \%$ of cases, the cost of CCS is lower than the carbon price, and the use of this technology is a viable proposition. Is it interesting to look at the percentage of effective GHG emission reduction via CCS in Fig. 20. When the climate sensitivity becomes high, the contribution of the CCS to the GHG abatement converges to $20 \%$. The figure also shows that when the climate constraint is low, this share is much higher and may even exceed $100 \%$. This result must be related to the hedging strategy that we have taken into account, and when the climate sensitivity is very low, the investment in CCS done before 2030 leads to an amount of $\mathrm{CO}_{2}$ sequestration above

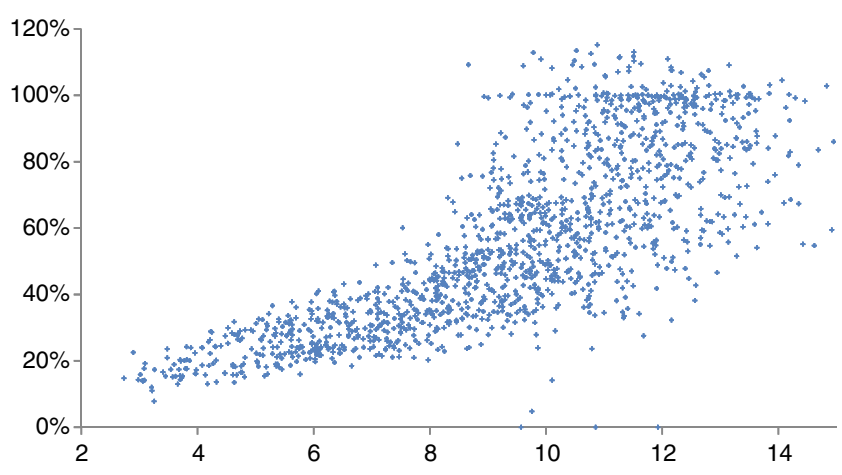

Fig. 20 Percentage of emission reductions effected via CCS in 2050 in respect to the GHG emissions in Gt C-eq 
Table 17 Percentage of emission reductions effected via CCS in 2050

\begin{tabular}{ll}
\hline DEMETER & $38 \%$ \\
GEMINI-E3 & $19 \%$ \\
TIAM WORLD & $75 \%$ \\
TIAMEC & $43 \%$ \\
WITCH & $11 \%$ \\
\hline
\end{tabular}

the GHG abatement required in 2050. We suppose in GEMINI-E3 that the CCS installed would not be removed, and it might be more realistic to assume that in these situations the sequestration facilities are disconnected from the power plant. This result also shows that sequestration is used first, and then when the abatement increases, the potential for sequestration is used to its maximum and peaks at $20 \%$ to the total reduction. We compared the results of GEMINI-E3 concerning the share of emissions sequestered with four other models in the case of a scenario in which we assume that the total atmospheric radiative forcing resulting from long lived greenhouse gases would not exceed $3.5 \mathrm{~W} / \mathrm{m}^{2}$ at any time during the twenty-first century. ${ }^{11}$ Table 17 indicates the percentages of $\mathrm{CO}_{2}$ emission reductions that are done via CCS in 2050. CCS appears to play a major role in the TIAM WORLD approach to $\mathrm{CO}_{2}$ abatement, an important role for TIAMEC and DEMETER and a more modest role for GEMINI-E3 and WITCH. These wide differences come not only from widely different assumptions on the potential for sequestration allowed in each model but also from the fact that TIAM WORLD is the only model having technological options for producing electricity, hydrogen and synthetic fuels from biomass with $\mathrm{CCS}$, which result in negative emissions of $\mathrm{CO}_{2}$. Such technologies are powerful ones when strong reductions are needed, and they are heavily adopted by the TIAM WORLD model. They go a long way in lowering the cost of abatement and thus the price of carbon as we saw in previous sections.

\subsubsection{Deterministic Equivalent Solution vs. MC Simulations}

To conclude this analysis on climate policy scenarios, we compare the results in the "average deterministic" run and the average of these results in the MC analysis runs. The most significant results are shown in Table 18.

These output values are remarkably different. We notice that the average deterministic run underestimates the carbon price in 2030 and the total cost.

\footnotetext{
${ }^{11}$ This corresponds roughly to a mean surface temperature increases between $2.23^{\circ} \mathrm{C}$ and $2.52^{\circ} \mathrm{C}$ with a climate sensitivity equal to 3 according to the TIAM WORLD model.
}

Table 18 Deterministic equivalent solution vs. MC simulations

\begin{tabular}{lcc}
\hline & $\begin{array}{c}\text { Deterministic } \\
\text { equiv. sol. }\end{array}$ & $\begin{array}{c}\text { Averages of MC } \\
\text { simulations }\end{array}$ \\
\hline $\mathrm{CO}_{2}$ price in 2030 & $\$ 17$ & $\$ 63$ \\
$\mathrm{CO}_{2}$ price in 2050 & $\$ 87$ & $\$ 84$ \\
$\begin{array}{c}\text { Discounted world } \\
\text { cost (trillion \$) }\end{array}$ & -3.8 & -8.0 \\
$\%$ of electricity & & $66 \%$ \\
generation done \\
by coal using CCS
\end{tabular}

This shows how misleading could be an analysis based only on the use of average values in a deterministic model, and this demonstrates the added insight on policy analysis that is brought by a stochastic analysis of these two models.

\section{Conclusion}

The purpose of this paper was to show the impact of uncertainty on the integrated assessment of climate policies. We identified four classes of uncertainties related to climate, technology, economy and energy prices, respectively. Several conclusions emerge from this work.

The main uncertainty is related to the climate sensitivity, and it is necessary to determine its value as soon as possible. Indeed, we showed that if the climate sensitivity is too high, simply the climate target cannot be achieved in the CGE model. This impossibility to meet stringent climate target has been also highlighted in the study done by the Energy Modeling Forum [10]. We also showed that the cost of climate policy is very dependent on the climate sensitivity, and when the GHG emission constraint is below 7 GtC-eq in 2050, the cost increases very rapidly reflecting the difficulty in reaching the climate target.

Concerning the technological aspects of climate policy, we found that the availability of carbon-free technologies is also determinant and that there is no single silver bullet to combat carbon emissions. Thus, according to the model, CCS alone cannot provide the solution to the problem of GHG emissions increase, and we must promote the development of a basket of carbon-free technologies. From this perspective, we must encourage not only the development of substitution among energy forms but also between energy and other inputs. This means also that we must encourage all substitutions and that the transition to a carbonfree economy asked to modify not only our production process but also our way of life itself. 
Our simulations have shown, however, that other factors are liable to affect the success and the cost of climate policy. The price of oil and behind it the behaviour of OPEC affects the possibility of reaching a target climate. The climate negotiation must therefore incorporate the specificities of these countries. Note that the oil exporting countries have always conditioned their participation in such an agreement to financial compensation transfers. The economic development of Asia is also a decisive factor in the cost and the success of a climate policy. China and India have to be integrated as soon as possible in the climate agreement.

Finally, we found that in $9 \%$ of runs, the climate target cannot be reached, and this means that if mitigation policies should be implemented, climate change adaptation policies must also be set up in parallel in case it would be simply impossible to achieve the target.

Acknowledgements This work was supported by the FP7 European Research Project PLANETS, by GICC Research Grant from the French Ministry of Ecology and Sustainable Development (MEDDTL) and by the Swiss-NSF-NCCR climate grant. For helpful comments and discussions, we thank A. Bousquet and R. Gerlagh. Two referees' comments have been most useful to improve the paper.

\section{References}

1. Allen, M. R., \& Frame, D. J. (2007). ATMOSPHERE: Call off the quest. Science, 318(5850), 582-583.

2. Andronova, N., \& Schlesinger, M. E. (2001). Objective estimation of the probability distribution for climate sensitivity. Journal of Geophysical Research, 106, 22605-22612.

3. Armington, P. S. (1969). A theory of demand for products distinguished by place of production. IMF Staff Papers, 16, 159-178.

4. Awerbuch, S., \& Sauter, R. (2006). Exploiting the oil? GDP effect to support renewables deployment. Energy Policy, 34(17), 2805-2819.

5. Azar, C., \& Dowlatabadi, H. (1999). A review of technical change in assessment of climate policy. Annual Review of Energy and the Environment, 24(1), 513-544.

6. Barsky, R. B., \& Kilian, L. (2004). Oil and the macroeconomy since the 1970s. Journal of Economic Perspectives, 18(4), 115134.

7. Bernard, A., \& Vielle, M. (2003). Measuring the welfare cost of climate change policies: A comparative assessment based on the computable general equilibrium model GEMINI-E3. Environmental Modeling \& Assessment, 8(3), 199-217.

8. Bernard, A., \& Vielle, M. (2008). GEMINI-E3, a general equilibrium model of international national interactions between economy, energy and the environment. Computational Management Science, 5(3), 173-206.

9. Blanchard, O. J., \& Gal, J. (2007). The macroeconomic effects of oil price shocks: Why are the 2000s so different from the 1970s? Technical report, MIT Department of Economics Working Paper No. 07-21.

10. Clarke, L., Edmonds, J., Krey, V., Richels, R., Rose, S., \& Tavoni, M. (2009). International climate policy architectures:
Overview of the EMF 22 international scenarios. Energy Economics, 31(Supplement 2), S64-S81. International, U.S. and E.U. Climate Change Control Scenarios: Results from EMF 22.

11. Conseil de l'Union Européenne (2008). Proposal for a decision of the European Parliament and of the Council on the effort of member states to reduce their greenhouse gas emissions to meet the community's greenhouse gas emission reduction commitments up to 2020. Technical report, 16736/ $1 / 08$.

12. Dimaranan, B. V. (2007). Global trade, assistance, and production: The GTAP 6 data base. West Lafayette: Center for Global Trade Analysis Purdue University, Center for Global Trade Analysis, Purdue University.

13. Edmonds, J., \& Reilly, J. (1985). Global energy: Assessing the future. New York: Oxford University Press.

14. Energy Information Administration (2009). International energy outlook 2009. Washington, DC: EIA/DOE.

15. Energy Information Administration (2010). International energy outlook. Technical report, U.S. Department of Energy.

16. European Commission (2007). World energy technology outlook-2050-WETO-H - update 2007.

17. Grubb, M., Khler, J., \& Anderson, D. (2002). Induced technical change in energy and environmental modeling: Analytic approaches and policy implications. Annual Review of Energy and the Environment, 27(1), 271-308.

18. Iman, R. L., \& Helton, J. C. (1988). An investigation of uncertainty and sensitivity analysis techniques for computer models. Risk Analysis, 8(1), 71-90.

19. Intergovernmental Panel on Climate Change (2007). Climate change 2007: Synthesis report. WMO and UNEP.

20. Johnsson, F., Berndes, G., \& Thunman, H. (2009). Report on technology: Bridging the gap. Technical report, FP7 European Research Project PLANETS (http://www.feem-project. net/planets/plastore/Deliverables/PLANETS_D10.pdf).

21. Jones, D. W., Leiby, P. N., \& Paik, I. K. (2004). Oil price shocks and the macroeconomy: What has been learned since 1996. The Energy Journal, 25(2), 1-32.

22. Kanudia, A., \& Loulou, R. (1998). Robust responses to climate change via stochastic markal: The case of Québec. European Journal of Operations Research, 106, 15-30.

23. Kypreos, S. (2008). Stabilizing global temperature change below thresholds: Monte Carlo analyses with merge. Computational Management Science, 5(1), 141-170.

24. Labriet, M., Loulou, R., \& Kanudia, A. (2010). Modeling uncertainty in a large scale integrated energy-climate model. In J. A. Filar, \& A. Haurie (Eds.), Handbook on "Uncertainty and environmental decision making". International series in operations research and management science (pp. 5178). Berlin: Springer.

25. Loulou, R. (2007). ETSAP-TIAM: The TIMES integrated assessment model. Part II: Mathematical formulation. Computational Management Science, 5(1), 7-40.

26. Loulou, R. (2009). Report on policy scenarios: Regional economic and energy implications of reaching global climate targets-A policy scenario analysis. Technical report, FP7 European Research Project PLANETS (http://www.feemproject.net/planets/plastore/Deliverables/PLANETS_D12.pdf).

27. Loulou, R., \& Kanudia, A. (1999). Minimax regret strategies for greenhouse gas abatement: Methodology and application. Operations Research Letters, 25, 219-230.

28. Loulou, R., \& Labriet, M. (2008). ETSAP-TIAM: The TIMES integrated assessment model. Part I: Model structure. Computational Management Science, 5(1), 7-40. 
29. Loulou, R., Labriet, M., \& Kanudia, A. (2009). Deterministic and stochastic analysis of alternative climate targets under differentiated cooperation regimes. Energy Economics, 31(Supplement 2), 131-143.

30. Manne, A. S., \& Richels, R. G. (1994). The costs of stabilizing global $\mathrm{CO}_{2}$ emissions: A probabilistic analysis based on expert judgment. Energy Journal, 15(1), 31-56.

31. Odenberger, M., \& Johnsson, F. (2010). Pathways for the European electricity supply system to 2050-The role of CCS to meet stringent $\mathrm{CO}_{2}$ reduction targets. International Journal of Greenhouse Gas Control, 4(2), 327-340

32. Odenberger, M., Käjrstad, J., \& Johnsson, F. (2008). Rampup of $\mathrm{CO}_{2}$ capture and storage within Europe. International Journal of Greenhouse Gas Control, 2, 417-438.

33. Regnier, E. (2007). Oil and energy price volatility. Energy Economics, 29(3), 405-427.

34. Reilly, J., Edmonds, J., Gardner, R., \& Brenkert, A. (1987). Monte Carlo analysis of the IEA/ORAU energy/carbon emissions model. The Energy Journal, 8(3), 1-29.

35. Roe, G. H., \& Baker, M. B. (2007). Why is climate sensitivity so unpredictable? Science, 318(5850), 629-632.

36. Scott, M. J., Sands, R. D., Edmonds, J., Liebetrau, A. M., \& Engel, D. W. (1999). Uncertainty in integrated assessment models: Modeling with MiniCAM 1.0. Energy Policy, 27(14), 597.

37. Siliverstovs, B., L'Hgaret, G., Neumann, A., \& von Hirschhausen, C. (2005). International market integration for natural gas? A cointegration analysis of price in Europe, North America and Japan. Energy Economics, 27(4), 603615.

38. United Nations Department of Economic and Social Affairs, Population Division 191 (2006). World population prospects: The 2004 revision, Volume III Analytical report. New York: United Nations.

39. Urga, G., \& Walters, C. (2003). Dynamic translog and linear logit models: A factor demand analysis of interfuel substitution in US industrial energy demand. Energy Economics, 25(1), 1-21.

40. van Vuuren, D. P., Weyant, J., \& de la Chesnaye, F. (2006). Multi-gas scenarios to stabilize radiative forcing. Energy Economics, 28(1), 102-120.

41. Webster, M. D., Babiker, M., Mayer, M., Reilly, J. M., Harnisch, J., Sarofim, M. C., et al. (2002). Uncertainty in emissions projections for climate models. Atmospheric Environment, 36(22), 3659-3670.

42. Webster, M., Paltsev, S., Parsons, J., Reilly, J., \& Jacoby, H. (2008). Uncertainty in greenhouse emissions and costs of atmospheric stabilization. Technical report, Joint Program Report Series, 61 pp. http://mit.globalchange.edu/pubs/abstract. php?publication_id=974.

43. Wing, I. S. (2006). The synthesis of bottom-up and top-down approaches to climate policy: Electric power technologies and the cost of limiting US $\mathrm{CO}_{2}$ emissions. Energy Policy, $34,3847-3869$. 